Federal Reserve Bank of Minneapolis

Research Department

\title{
Private Money Creation and the Suffolk Banking System*
}

\author{
Bruce D. Smith and Warren E. Weber
}

Working Paper 591

October 1998

*Smith, University of Texas at Austin; Weber, Federal Reserve Bank of Minneapolis. The views expressed herein are those of the authors and not necessarily those of the Federal Reserve Bank of Minneapolis or the Federal Reserve System. 
Recent legislative developments have removed the legal impediments to private banknote issue in the U.S. At the same time, improvements in transaction technologies have made it possible for banks - or other entities - to issue various forms of "e-cash." For all practical purposes, e-cash is the electronic equivalent of a banknote. As a consequence of these facts, it is quite likely that developed economies will soon see a reemergence of privately issued substitutes for currency.

What will be the economic consequences of private note issue, or its electronic counterparts? Neither recent monetary theory, nor recent monetary experience - at least in the U.S. provides much of an answer to this question. Note issuance by U.S. banks ceased in the late $1920 \mathrm{~s},{ }^{1}$ and theoretical interest in the topic of private note issue largely ceased along with it. As a result, we must rely primarily on historical experience for guidance about the monetary impact of private note creation.

A first obvious concern suggested by the historical record is the following. With many private issuers of notes, will we have a monetary system with several kinds of monies all circulating at various premia or discounts? Before the federal government took control of private note creation during the Civil War, the U.S. had a large number of state chartered banks that issued notes. Despite the requirement that these banks stand ready to redeem their notes for specie on demand, banknotes typically circulated at a discount outside their location of origin. And this was perceived to be a continual problem throughout the first 80 years of U.S. monetary history.

An exception to this statement was the New England region during the 35 years prior to the Civil War. There a private bank - the Suffolk Bank of Boston—created a note clearing sys-

${ }^{1}$ Canadian banks issued notes until much later. Of course, private note issue still persists in other places. For example, private banks issue notes in Hong Kong, albeit under the aegis of a currency board. 
tem in which it stood ready to accept the notes of member banks at par. The result was a substantial achievement: all notes of Suffolk Banking System members circulated at par throughout New England. This system was duplicated nowhere else in the U.S.

Because most of the U.S. had a problematic experience with private note issuethere were routinely discounts and premia on notes with identical face values, not to mention panics and periodic episodes of significant default risk on notes ${ }^{2}$ - many have argued that the issue of currency or close currency substitutes should either be regulated, or should be a government monopoly. ${ }^{3}$ Others have argued that money creation can safely be "left to the market."4 Supporters of this view often point to the Suffolk Banking System as an example of a wellfunctioning system of private money creation. This fact alone makes it important to revisit this system.

While much has been written on the history of the Suffolk Banking System, somewhat surprisingly (to our knowledge) no attempt has been made to formally model its monetary consequences. In this paper we attempt to fill this gap. In particular, we build a model in which private banks issue notes that circulate alongside a stock of outside money. These notes might or might not circulate at a discount (outside their location of origin). We then analyze two different banking arrangements. One has no centralized system for clearing banknote issues at par. The second has such an arrangement, and its features are meant to duplicate important monetary aspects of the Suffolk Banking System. We characterize and compare competitive equilibria of the two systems along several dimensions. And, we also "take our model to the data," using a newly

\footnotetext{
${ }^{2}$ For example, see Rockoff (1975) or Rolnick and Weber $(1983,1984,1988)$ on experience under so-called "free banking."

${ }^{3}$ See Friedman (1960) for a forceful articulation of this view.

${ }^{4}$ See, for instance, Hayek (1976).
} 
developed data set on antebellum banks to compare the predictions of the model with the behavior of a set of banks that did and did not operate in the context of the Suffolk Banking System.

What bases should we use for a comparison of the two banking arrangements? Clearly one is welfare, and we do analyze steady state welfare in the presence and the absence of a Suffolk Banking System. Other criteria for assessing the performance of the two systems are suggested by the extensive historical debate on the "pros" and "cons" of allowing relatively unrestricted private note issue. For example, many authors ${ }^{5}$ have asserted that unrestricted private money creation allows considerable scope for indeterminacy and excessive volatility that would not otherwise be possible. Thus we focus to a large extent on the potential for indeterminacy and endogenous volatility that might arise either in the presence of a Suffolk-like system or in its absence. We also devote considerable attention to the potential for a certain kind of bank panic to occur, and we ask whether the presence of a Suffolk Banking System in and of itself is likely to curb the potential for panics.

Our vehicle for addressing these issues is an overlapping generations model that emphasizes the importance of spatial separation and limited communication. As in Townsend (1987), these features generate a transactions role for currency. In addition, as in Champ, Smith, and Williamson (1996) or Schreft and Smith $(1997,1998)$ we introduce idiosyncratic "liquidity preference shocks." These shocks create a role for banks that is familiar from Diamond and Dybvig (1983). We then allow these banks to "lend," hold monetary reserves, and print notes. And, we

\footnotetext{
${ }^{5}$ Most notably Friedman (1960), but see Mints (1945) for an historical compendium.
} 
describe monetary equilibria of the economy in the presence and the absence of a Suffolk Banking System.

In the absence of a Suffolk Banking System, we find that there is considerable scope for both indeterminacy of equilibrium and for endogenously arising volatility. If agents are relatively risk averse, there is only a fairly conventional "initial conditions" indeterminacy. However, depending on endogenous initial conditions, an economy can easily display either damped or undamped oscillation. Indeed, it is straightforward to state conditions under which the economy can exhibit a countable infinity of equilibria where inflation, interest rates, and note discounts evolve according to cycles of high order.

When agents are not very risk averse, there is still an initial conditions indeterminacy. However, an additional indeterminacy also arises that is not typically present in conventional monetary models, and it too can give rise either to damped or undamped oscillation. In particular, at any date the economy can be in one of two "regimes." In one regime banks issue notes that are not discounted; in the other regime there are discounts on banknotes. The economy can transit between these regimes either deterministically or stochastically, and it is these "regime transitions" that are the source of the additional indeterminacy. Interestingly, as the economy transits from a regime with no discounts on notes to one with discounts, not only do note discounts increase, but so too do nominal rates of interest. At the same time specie reserves (or outside money reserves) held by banks drop. Thus regime transitions are accompanied by several of the monetary phenomena we typically associate with bank panics. And we show that it can easily happen that the economy ends up in equilibria where there are infrequent panics, but that panics are of long duration when they do occur. This is certainly consistent with events (outside of New England) surrounding the panics of 1819 and 1837. 
In the presence of a Suffolk-like system, matters are somewhat different. In particular, when a Suffolk Banking System operates, it eliminates the discount on banknote issues. Consequently, it is not possible for the economy to transit between regimes that are distinguished by the presence or absence of note discounts. Thus the existence of a Suffolk Banking System eliminates one source of indeterminacies. However, it does not eliminate indeterminacies arising from the endogeneity of initial conditions. Nor does the presence of a Suffolk-style system eliminate — or even necessarily reduce — the scope for endogenously generated volatility. Indeed, we analyze an example (one where agents are not very risk averse) which has the feature that endogenous volatility cannot be observed in the absence of a Suffolk Banking System. In the presence of such a system, however, both damped and undamped oscillations in inflation and interest rates can be observed. Thus it is a distinct theoretical possibility that the creation of a Suffolkstyle system can substantially enhance volatility. Moreover, some equilibria under this system will display sharp periodic declines in bank reserves and large increases in nominal interest rates. To the extent that these occurrences are associated with bank panics, these are not necessarily eliminated by the introduction of a Suffolk Banking System.

Our analysis predicts that, under a certain set of conditions, the existence of a Suffolkstyle system will raise steady state welfare, and can lead to endogenous volatility. We argue that it is empirically plausible that these conditions were satisfied historically. We then show that members of the Suffolk Banking System appear to have held relatively low levels of specie reserves - a necessary condition for the presence of a Suffolk-like Banking System to enhance steady state welfare. We also argue that while the banks belonging to the Suffolk System appear to have weathered panics better than banks elsewhere, in general the Suffolk Banking System did 
not lead to less volatile financial conditions than those observed elsewhere. All of these findings are, of course, consistent with our theoretical analysis.

The remainder of the paper proceeds as follows. Section 1 gives an overview of the historical Suffolk Banking System, emphasizing aspects that are relevant to our analysis. Section 2 describes the model environment, while Section 3 lays out the role for banks and their general behavior. Sections 4 and 5 characterize bank behavior - as well as the properties of a general equilibrium-in the absence of a Suffolk-like system. Sections 6 and 7 do the same when a Suffolk Banking System is present. Section 8 analyzes steady state welfare under the two alternative banking arrangements. Section 9 describes some empirical implications of the model and contrasts them with historical observation. Section 10 offers some concluding remarks.

\section{The Suffolk Banking System: An Overview ${ }^{6}$}

Between 1825 and the Civil War, the bulk of the U.S. money supply consisted of notes issued by private banks. ${ }^{7}$ With one important exception these were state chartered banks.

Typically bank charters or other regulations required banks to redeem their own notes at par on demand. But notes circulating sufficiently far away from their location of origin often exchanged at a discount relative to local bank notes. It has been commonly suggested that these discounts reflected the distance of the notes from their location of issue (as a proxy for redemp-

\footnotetext{
${ }^{6}$ This section is intended only to highlight features of the Suffolk Banking System that are relevant to this study. For comprehensive discussions of the history of the Suffolk Banking System see Whitney (1878), Lake (1947), and Redlich (1947). A concise summary of this history appears in Rolnick, Smith, and Weber (1998).

${ }^{7}$ Temin (1969) estimates that in 1835 only about 11 percent of the money supply consisted of specie. Federal and state governments at this time did not directly issue any paper currency.

During its heyday, about 20 percent of banknotes were issued by the federally chartered Second Bank of the U.S. This bank lost its federal charter in 1836, and ceased all operations in 1841. Twenty percent of Second Bank stock was owned by the federal government. Parenthetically, the Second Bank was never very important in New England.
} 
tion costs), as well as the default risk of the issuer. The notes of most banks situated in the same location circulated at essentially the same discount in any other location (Gorton 1989).

However, from about 1826 on, the notes of the vast majority of New England banks circulated at par throughout New England. This was an accomplishment of the Suffolk Banking System, a private note clearing and correspondent banking arrangement established by the Suffolk Bank of Boston. ${ }^{8}$

The incarnation of the Suffolk Banking System relevant to this paper began in 1824 as a scheme on the part of Boston banks to reduce the circulation of the notes of non-Boston banks in Boston. $^{9}$ This scheme quickly failed. But the Suffolk Banking System survived when the Suffolk Bank opted to allow all system members to deposit with it all notes issued by other system members at par. Suffolk also established the first net clearing system in the U.S. to deal with the notes deposited. Notes of non-system members received by Suffolk were returned to the issuing bank for immediate redemption. In addition, Suffolk offered loans to system members at a time when the market for interbank credit appears to have been generally underdeveloped. As a result of its note acceptance and clearing strategy, the notes of all system members circulated at par throughout New England. Thus members of the Suffolk Banking System obtained (a) generalized par circulation of their notes, (b) the right to deposit notes at par with Suffolk, (c) the note clearing services of Suffolk (which appear to have been highly efficient), and (d) access to credit from Suffolk.

\footnotetext{
${ }^{8}$ The Suffolk Banking System is sometimes described as having been operated by a coalition of Boston banks. For various reasons (see Rolnick, Smith, and Weber (1998)) we do not think this is accurate. However this point is not important for our purposes.

${ }^{9}$ According to Mullineaux (1987), over half of the bank notes circulating in Boston between 1812 and 1844 were issued by non-Boston banks.
} 
In order to belong to the Suffolk Banking System, non-Boston banks had to maintain two types of noninterest bearing deposits with Suffolk (or some other designated Boston banks). First they had to maintain a "permanent" deposit equal to 2 percent of their capital (which was generally specified by their charter). Second, they had to maintain an additional deposit that was, on average, sufficient to redeem their notes that Suffolk received. For Boston banks matters were somewhat different: they had only to maintain a noninterest bearing permanent deposit. ${ }^{10}$

By 1836, about 300 New England banks - comprising the vast majority of banks in New England - were members of the Suffolk Banking System. As we have observed, all of their notes circulated at par throughout New England. And, Suffolk became by far the largest holder of interbank deposits in New England, holding about three times as many of these deposits in 1835 as any other New England bank. Suffolk also became a very large interbank lender. While for various reasons this is difficult to sort out exactly, in the late 1830s Suffolk had interbank loans at least five times as large as those of any other New England bank. In 1857, Suffolk's interbank loans were at least ten times as large as those of any other New England bank.

As we have argued elsewhere, Suffolk was essentially a monopolist in the provision of these services. Thus it is not unreasonable to treat Suffolk as if it could freely set terms for membership, as well as terms on interbank loans.

The volume of banknotes cleared by Suffolk was very large. In 1858 Suffolk cleared nearly $\$ 30,000,000$ of notes per month: a figure in excess of the total note issue of all Massachusetts banks. Moreover, after 1843 banks were obligated to clear any notes issued by other banks, since after that date Massachusetts prohibited banks from paying out the notes of other banks over their own counters. In fact, this essentially obligated banks to clear all the notes of

\footnotetext{
${ }^{10}$ This was originally set at $\$ 30,000$, but was reduced over time to $\$ 5,000$.
} 
other banks that they received. To do this, they either had to engage in relatively expensive direct gross clearing, or they could avail themselves of the net clearing services of Suffolk.

We now turn our attention to the analysis of the monetary consequences of the creation of a Suffolk-style banking system in a world with private banknote issue.

\section{The Environment}

We consider an economy consisting of an infinite sequence of two-period lived, overlapping generations. Let $t=1,2, \ldots$ index time. At each date the population is divided among two distinct locations (islands); let $j=1,2$ index locations. In each period and in each location a new young generation is born consisting of a continuum of ex ante identical agents with unit mass.

When young, each agent is endowed with $w>0$ units of a single consumption good. This can either be consumed or stored. One unit stored at $t$ yields $x>1$ units of consumption at $t+1$. We assume throughout that agents have no goods endowment when old.

For simplicity we assume that agents care only about second period consumption, which we denote by $c{ }^{11}$ The utility function of these agents, $u(c)$, has the CRRA form

$$
u(c)=c^{1-\rho} /(1-\rho) ; \rho>0 .
$$

The essential features of our analysis are (i) the spatial separation of agents, (ii) limited communication across locations, and (iii) stochastic relocation. The first two features are introduced to create a transactions role for currency (Townsend 1987). The third feature is added to create a role for banks that provide liquidity—here by holding reserves and issuing notes (Dia-

\footnotetext{
${ }^{11}$ This assumption merely allows us to abstract from any first period consumption/savings decision by agents. Introducing such a decision would not alter any of our results, but it would require additional notation.
} 
mond and Dybvig 1983; Champ, Smith, and Williamson 1996; Schreft and Smith 1997,1998). We now describe how these features impact on transactions.

At the beginning of period $t$ young agents receive their endowment. Since young agents do not wish to consume they will either store their endowment, ${ }^{12}$ or sell part of it to old agents who inhabit the same location. In particular, agents must be "together" in order to trade: interlocation exchange is not physically possible.

After agents engage in storage and exchange, some fraction of young agents is selected at random to be relocated (moved to the other location). Let $\pi$ be the probability that any young agent will be chosen to relocate. Then in each period a fraction $\pi$ of the population moves, and a fraction $1-\pi$ does not.

The significance of this relocation is that stored goods cannot be transported between locations (say they are "planted" and must be left until a future harvest). Therefore, agents who are relocated must acquire claims on consumption in their new location. Nor will arbitrary claims do, since we assume that at the time transactions occur, communication between the locations cannot occur. This assumption prevents relocated agents from using arbitrary claims-like checks or credit cards - issued against agents in their location of origin. ${ }^{13}$ We will describe the assets used by relocated agents below.

The stochastic nature of this relocation allows relocations to act like a "liquidity preference" shock in the Diamond-Dybvig (1983) model. In particular, relocated agents must liquidate any claims to storage in favor of "more liquid," but potentially lower yielding assets. As in

\footnotetext{
${ }^{12}$ As we will see, the endowment may be stored either directly, or indirectly through an intermediary.

${ }^{13}$ See Champ, Smith, and Williamson (1996) for a further discussion, and for a defense of the realism of this assumption when applied to 19th century economies.
} 
Diamond-Dybvig, agents will wish to be insured against this possibility. Such insurance can be provided by banks, as we now describe.

\section{Trade}

There are two primary assets in this economy: storage and fiat money. ${ }^{14}$ We let $M_{t}$ denote the outstanding stock of outside (government issued) money at $t$, per capita, and we assume that $M_{t}$ evolves according to

$$
M_{t}=\sigma M_{t-1} ; t \geq 1
$$

with $\sigma \geq 1$ exogenously set by the government, and with $M_{0}>0$ given. ${ }^{15}$ Throughout we assume that $M_{t}$ is the same in each location.

If $\sigma>1$ holds, the government earns seigniorage revenue. For simplicity, we assume that this revenue is used to finance an endogenous sequence $g_{t}$ of government expenditures. If $p_{t}$ is the time $t$ price level, then

$$
g_{t}=\left(M_{t}-M_{t-1}\right) / p_{t}=[(\sigma-1) / \sigma] M_{t} / p_{t}
$$

holds.

\footnotetext{
${ }^{14}$ Alternatively, we could imagine a commodity money that does not depreciate, and which agents choose to augment at some constant rate (possibly zero). Under this reinterpretation of the model what we call "seigniorage revenue" should be regarded as resources utilized to augment the stock of commodity money. See Sargent and Wallace (1983) for a model of this type that could be modified to "fit" our economy.

In addition, as in Sargent and Wallace, we can imagine that an ability to convert goods into gold or silver and gold or silver into goods puts an upper and a lower bound on the price level. If those bounds are sufficiently far apart (in a small open economy, for example, if transportation costs are sufficiently large), then we can make auxiliary assumptions so that all of our results translate intact into a model of commodity money.

${ }^{15}$ The initial old agents at $t=1$ are endowed with the initial money supply, $M_{0}$. Thereafter agents have no endowments of money.
} 
Young agents could hold the primary assets in the model-money and storage-directly. If they do so, they obtain only self-insurance against the event of being relocated. ${ }^{16}$ Our assumptions imply that agents will often want to obtain additional insurance, which can be provided by a Diamond-Dybvig style intermediary.

In keeping with the nature of 19th century U.S. banking, we assume that banks take deposits and hold the model's primary assets, money, and storage. In addition, we assume that banks can issue their own notes. Typical charters and banking laws required banks to redeem their notes in outside money on demand, and so we assume that each bank must exchange one dollar in outside money for a dollar of its notes whenever called upon to do so.

However, if a bank has issued a note that is currently held "in the other location," spatial separation and limited communication imply that that note cannot immediately be redeemed. Hence it is possible that notes circulating in the other location exchange at a discount for currency. Let $e_{t}$ denote the discount (if $e_{t}<1$ ) or premium (if $e_{t}>1$ ) on a note circulating away from its location of origin. ${ }^{17}$ Thus $e_{t}$ is the exchange rate between privately and publicly issued monies at $t$.

In summary, then, banks have two assets; storage and cash reserves. They also have two liabilities; notes and deposits. We let $k_{t}$ denote per depositor storage by a representative bank at $t$, and $m_{t}$ be the real value of cash reserves held at the beginning of period $t$, again per depositor.

\footnotetext{
${ }^{16}$ In particular, we assume that young agents do not meet each other again after learning their relocation status. This assumption is similar to one made by Wallace (1988).

${ }^{17} \mathrm{We}$ focus only on equilibria where the discount is the same for all banks, and is the same in each location. The former idea reflects the historical fact that the notes of most banks situated in the same location circulated at the same discount: what Gorton (19xx) terms the "modal discount." The second reflects the notion that discounts largely reflected distance from the issuing bank when default risk was absent, as it is here.
} 
$b_{t}$ denotes the real value of the notes issued by a representative bank at $t$ (per depositor)-if they circulate at face value (as they must in their location of origin). ${ }^{18}$

Since goods in storage cannot be transported between locations, relocated agents must acquire cash — either currency or banknotes — in order to transact in their new location. Thus, in effect, goods purchased in one's location of origin are "credit goods"; all other goods are "cash goods." And, by implication, young agents who made a bank deposit and are then relocated will stop at their bank, and withdraw their deposits accepting either currency or banknotes in exchange. This timing of events is depicted in Figure 1.

In view of this discussion, we model bank behavior as follows. Each bank chooses a value $k_{t}$ for the quantity of resources it will store at $t$ (all variables are in "per depositor" terms) and a value $m_{t}$ for the real value of its cash reserves. The bank will also issue notes at $t$ with a real value (in their current location) of $b_{t}$. Finally, the bank chooses a vector of real returns received by depositors which we denote by $\left(d_{t}^{m}, d_{t}^{n}\right){ }^{19} d_{t}^{m}\left(d_{t}^{n}\right)$ is the gross real return between $t$ and $t+1$ received by agents who make a deposit and then move (don't move) between locations.

Obviously these choices by the bank are subject to some constraints. An important issue in formulating these constraints is when notes issued by a bank at $t$ are presented for redemption. Here we focus on equilibria where all notes are redeemed at the earliest opportunity: in this case one period after issue. We do not take up the question of whether or not other equilibria with longer periods between issue and redemption are possible. However, we do observe that, in Massachusetts, banks were prohibited from paying out the notes of other banks. In the equilibria

\footnotetext{
${ }^{18}$ As before, we assume that these values are the same - in equilibrium — across locations.

${ }^{19}$ Since we consider nonstochastic economies where agents have perfect foresight, it does not matter whether the bank quotes real or nominal returns to agents.
} 
constructed here, such a restriction would imply that all notes be cleared among banks (redeemed) at the first opportunity. ${ }^{20}$

We now describe the equilibrium behavior of banks. We focus first on banks that operate without a Suffolk-like entity. We then turn our attention to bank behavior when a Suffolk Banking System is in place.

\section{Banking With Decentralized Clearing Arrangements}

A bank that operates in the absence of a Suffolk Banking System faces the following constraints. First, the value of the assets it acquires cannot exceed the value of its deposits $(w):^{21}$

$$
m_{t}+k_{t} \leq w ; t \geq 1
$$

Second, agents who are relocated must be paid either with currency, or with notes issued by the bank. Let $\alpha_{t} \in[0,1]$ denote the fraction of its cash reserves that a representative bank carries between $t$ and $t+1$. Then, since a fraction $\pi$ of its depositors will be relocated, the bank's announcement of $d_{t}^{m}$ must satisfy

$$
\pi d_{t}^{m} w \leq\left(1-\alpha_{t}\right) m_{t}\left(p_{t} / p_{t+1}\right)+b_{t} e_{t+1}\left(p_{t} / p_{t+1}\right)
$$

Equation (2) asserts that payments to depositors who are relocated cannot exceed the value of its reserves that the bank pays out $\left[\left(1-\alpha_{t}\right) m_{t}\right]$ plus the value of the notes that it issues $\left(b_{t}\right)$. In addition, $d_{t}^{m}$ represents the gross real return received by relocated agents between $t$ and $t+1$. Between the time that agents withdraw (acquiring money) and the time they transact, the real value

\footnotetext{
${ }^{20}$ The idea that banknotes are redeemed promptly is also consistent with the high observed volumes of banknote clearing under the Suffolk Banking System. See Rolnick, Smith, and Weber (1998).

${ }^{21}$ As in Diamond and Dybvig (1983), it is easy to verify that all savings are intermediated, in equilibrium, if net nominal interest rates are strictly positive. If net nominal interest rates are zero, not all savings need be intermediated.
} 
of their money will have increased/declined by the gross amount $p_{t} / p_{t+1}$. Hence the presence of this term on the right-hand side of (2). Finally, notes in the other location will circulate at the discount/premium $e_{t+1}$ at $t+1$, so if the bank issues notes with a real value of $b_{t}$ at $t$, these will be worth $b_{t} e_{t+1}\left(p_{t} / p_{t+1}\right)$ in "the other" location at $t+1$.

Third, nonrelocated agents must be paid at $t+1$ out of the bank's gross income from storage, $x k_{t}$, and its income from holding unliquidated reserves. In addition, at $t+1$, the bank must redeem the notes it issued at $t$. Consequently

$$
(1-\pi) d_{t}^{n} w \leq \alpha_{t} m_{t}\left(p_{t} / p_{t+1}\right)+x k_{t}-b_{t}\left(p_{t} / p_{t+1}\right) ; t \geq 1
$$

must hold.

We assume that banks compete against each other for individual deposits. We seek a Nash equilibrium where - given the choices of other banks - no bank has an incentive to alter its own choices $d_{t}^{m}, d_{t}^{n}, m_{t}, k_{t}, b_{t}$, and $\alpha_{t}$. This competition among banks for depositors will imply that, in equilibrium, the choices of active banks must maximize the expected utility of depositors subject to (1)-(3) and nonnegativity constraints. In particular, banks choose $d_{t}^{m}, d_{t}^{n}, m_{t}, k_{t}, b_{t}$, and $\alpha_{t}$ to solve the problem

$$
\max \pi\left(d_{t}^{m} w\right)^{1-\rho} /(1-\rho)+(1-\pi)\left(d_{t}^{n} w\right)^{1-\rho} /(1-\rho)
$$

subject to (1)-(3).

We now transform the problem of the bank as follows. Define

$$
\gamma_{t} \equiv m_{t} / w
$$

to be the bank's reserve-deposit ratio. Using this definition in (2) and (3), solve (3) for $b_{t}\left(p_{t} / p_{t+1}\right)$ and substitute the result into (2) to obtain

$$
\pi d_{t}^{m}+(1-\pi) d_{t}^{n} e_{t+1} \leq \gamma_{t}\left[\left(1-\alpha_{t}\right)+\alpha_{t} e_{t+1}\right]\left(p_{t} / p_{t+1}\right)+e_{t+1} x\left(1-\gamma_{t}\right) ; t \geq 1
$$


Then we can view banks as choosing $d_{t}^{m}, d_{t}^{n}, \gamma_{t} \in[0,1]$ and $\alpha_{t} \in[0,1]$ to solve the problem

$$
\max \pi\left(d_{t}^{m}\right)^{1-\rho} /(1-\rho)+(1-\pi)\left(d_{t}^{n}\right)^{1-\rho} /(1-\rho)
$$

subject to (4).

Evidently, whenever the bank holds some reserves, the optimal choice of $\alpha_{t}$ (the bank's reserve liquidation strategy) satisfies

$$
\alpha_{t}\left\{\begin{array}{l}
=0 ; e_{t+1}<1 \\
\in[0,1] ; e_{t+1}=1 . \\
=1 ; e_{t+1}>1
\end{array}\right.
$$

Equation (5) asserts that if its notes are discounted elsewhere, the bank should liquidate all its reserves to pay relocated depositors. In particular, its notes are inferior to currency (outside money) as a transactions medium, and relocated depositors will take banknotes only if cash reserves are exhausted. Similarly, if the bank's notes are at a premium elsewhere, they are superior to currency and depositors will want to be paid entirely in banknotes. Finally, if $e_{t+1}=1$ currency and banknotes are perfect substitutes, and depositors, as well as banks, are indifferent regarding reserve liquidation strategies.

It is also evident that the bank will hold both outside money reserves and goods in storage $\left[\gamma_{t} \in(0,1)\right]$ iff

$$
e_{t+1} x\left(p_{t+1} / p_{t}\right)=1-\alpha_{t}+\alpha_{t} e_{t+1}
$$

When (6) holds, the bank and its depositors are indifferent regarding portfolio composition. This must be determined as part of a general equilibrium. However, it is straightforward to determine $d_{t}^{m}$ and $d_{t}^{n}$. In particular, when (5) and (6) hold, $d_{t}^{m}$ and $d_{t}^{n}$ solve the problem

$$
\max \pi\left(d_{t}^{m}\right)^{1-\rho} /(1-\rho)+(1-\pi)\left(d_{t}^{n}\right)^{1-\rho} /(1-\rho)
$$

subject to 


$$
\pi d_{t}^{m}+(1-\pi) d_{t}^{n} e_{t+1} \leq e_{t+1} x
$$

The solution to this problem sets

$$
\begin{aligned}
& d_{t}^{m}=\left(e_{t+1}\right)^{1 / \rho} d_{t}^{n} \\
& d_{t}^{n}=x /\left[1-\pi+\pi\left(e_{t+1}\right)^{(1-\rho) / \rho}\right] .
\end{aligned}
$$

\section{A General Equilibrium With Decentralized Clearing Arrangements}

In a general equilibrium with no Suffolk Banking System, an equilibrium must satisfy several conditions. First, (1), (5), and (6) must be satisfied. Second, given the evolution of the money supply, the supply of and the demand for real balances must be equated. Since all beginning of period demand for real balances derives from banks' demands for reserves, it follows that

$$
M_{t} / p_{t}=\gamma_{t} w=m_{t} ; t \geq 1
$$

Third, goods markets must clear in each location. The "sources" of goods at $t$ are endowments, $w$, plus the proceeds of the previous period's storage, $x k_{t-1}$. "Uses" of goods are new storage, $k_{t}$, plus government expenditures, $m_{t}(\sigma-1) / \sigma$, plus the consumption of old agents currently residing in the relevant location. At date $t$, there is a mass $\pi$ of agents who have come from the other location. These agents hold claims with a consumption value of $w d_{t-1}^{m}$. Similarly, there is a mass $1-\pi$ of agents who were not relocated. These agents hold claims on banks entitling them to $w d_{t-1}^{n}$ units of consumption. Thus the goods market clears at $t$ if $^{22}$

$$
x k_{t-1}+w=k_{t}+m_{t}(\sigma-1) / \sigma+\left[\pi d_{t-1}^{m}+(1-\pi) d_{t-1}^{n}\right] w ; t \geq 2 .
$$

${ }^{22}$ At $t=1$ we must regard old agents in each location as endowed with the initial money supply, and possibly previously stored goods. They have no claims derived from bank deposits. It is easy to show that $m_{1}$ is a free initial condition. 
An alternative - and more useful—-representation of the goods market clearing condition is obtained by substituting (1), (8), (9), (10), and the definition of $\gamma_{t}$ into (11):

$$
\gamma_{t+1}+\sigma x\left(1-\gamma_{t}\right)=\sigma x\left\{\frac{(1-\pi)+\pi\left(e_{t+1}\right)^{1 / \rho}}{(1-\pi)+\pi\left(e_{t+1}\right)^{(1-\rho) / \rho}}\right\} .
$$

Equations (5), (6), (10), and (12) constitute the equilibrium conditions of the model in the absence of a Suffolk Banking System.

As will be apparent from a consideration of (5) and (6), periods in which $e_{t+1} \geq 1$ must be treated differently from periods in which $e_{t+1}<1$. We now consider each case separately.

\section{A. Periods in Which Notes Are not Discounted}

Suppose that $e_{t+1} \geq 1$ holds. Then it follows from (5) and (6) that $p_{t} / p_{t+1}=x>1$. In addition, equation (10) then implies that

$$
\gamma_{t+1}=\sigma x \gamma_{t}>\gamma_{t}
$$

Since $\gamma_{t+1} \leq 1$ must hold for all $t$, the following result is immediate:

Proposition 1. There is no equilibrium with positive real balances, and with $e_{t+1} \geq 1$ for all $t$.

Intuitively, this economy naturally has a positive real rate of interest $(x>1)$. Unless nominal interest rates are zero, banks perceive an arbitrage opportunity from printing notes if they are not discounted. But, in order for the nominal rate to be zero at $t$, there must be a deflation so that $p_{t} / p_{t+1}=x$. This requires that real balances rise more rapidly than the economy can sustain indefinitely. Hence, banknotes must ultimately go at a discount.

However, it is possible that there is either a finite or an infinite number of dates at which banknotes are not discounted. The following proposition describes equilibria at such dates. 
Proposition 2. Suppose that banknotes are not discounted at $t+1$. Then $e_{t+1}=1$ and $\gamma_{t+1}=$ $\sigma x \gamma_{t}$

The proof of Proposition 2 appears in Appendix A. The proposition asserts that banknotes never circulate at a premium. We now describe what happens in periods where banknotes are discounted. As we have observed, there must be periods in which this occurs.

\section{B. Periods in Which Notes are Discounted}

If $e_{t+1}<1$ holds, so that banknotes circulate at a discount, then (5) and (6) imply that

$$
e_{t+1}=p_{t} / x p_{t+1}=\gamma_{t+1} / \sigma x \gamma_{t}
$$

where the last equality follows from (10). Substituting (14) into (12) yields the equilibrium law of motion when notes are discounted:

$$
\gamma_{t+1}+\sigma x\left(1-\gamma_{t}\right)=\sigma x\left\{\frac{(1-\pi)+\pi\left(\gamma_{t+1} / \sigma x \gamma_{t}\right)^{1 / \rho}}{(1-\pi)+\pi\left(\gamma_{t+1} / \sigma x \gamma_{t}\right)^{(1-\rho) / \rho}}\right\}
$$

For further future reference, it will be useful to define the function $f$ by

$$
f(z) \equiv \sigma x\left\{\left[(1-\pi)+\pi z^{1 / \rho}\right] /\left[(1-\pi)+\pi z^{(1-\rho) / \rho}\right]\right\} .
$$

Then we can write (15) more compactly as

$$
\gamma_{t+1}+\sigma x\left(1-\gamma_{t}\right)=f\left(\gamma_{t+1} / \sigma x \gamma_{t}\right)
$$

Clearly it will be of value to state some properties of the function $f$.

Lemma 1. The function $f$ satisfies
(a) $\sigma x>f(1 / \sigma x)>1$.
(b) $\lim _{z \rightarrow \infty} f(z)=\infty$
(c) $f^{\prime}(z) \leq 0$ holds iff 


$$
\pi \rho z^{(1-\rho) / \rho} \leq(1-\pi)\left[(1-\rho) z^{-1}-1\right]
$$

Lemma 1 is proved in Appendix B.

It will typically be convenient to have an even sharper characterization of the equilibrium law of motion for $\gamma_{t}$ than $\left(15^{\prime}\right)$ provides. The following proposition provides such a characterization.

Proposition 3. Suppose that $\rho \neq 1$ holds. ${ }^{23}$ Then $\gamma_{t}$ evolves according to

$$
\gamma_{t+1}=\sigma x \gamma_{t}\left[\left(\frac{1-\pi}{\pi}\right)\left(\frac{\gamma_{t}}{1-\gamma_{t}}\right)\right]^{\frac{\rho}{1-\rho}}
$$

in all periods for which $e_{t+1}<1$.

The proof of proposition 3 appears in Appendix C.

Below we illustrate some possibilities with respect to dynamical equilibria. However, we begin with an analysis of steady state equilibria.

\section{Steady States}

In a steady state, clearly we have $e_{t+1}=e_{t}=e=1 / \sigma x<1$, by (14). In addition, it is easy to verify that there is a unique steady state value of $\gamma$, satisfying

$$
\gamma_{t+1}=\gamma_{t}=\gamma^{*} \equiv \frac{\sigma x-f(1 / \sigma x)}{\sigma x-1} \in(0,1)
$$

Notice that, in a steady state equilibrium, the gross nominal interest rate is given by $I_{t}=x p_{t+1} / p_{t}=$ $\sigma x>1$. The steady state discount on notes is therefore $e=I^{-1}$. Intuitively, if its notes are not

\footnotetext{
${ }^{23}$ The case $\rho=1$ is considered below.
} 
discounted, positive nominal interest rates give a bank incentives to print arbitrarily large quantities of notes. Thus, to prevent this from happening, banks must face a cost of issuing notes. A discount provides this: the current resources that can be raised by issuing notes are less than the future cost of redeeming them. When the ratio of these costs is the nominal interest rate $(1 / e=$ I), the net gain to the bank from issuing notes disappears, as do the arbitrage opportunities perceived by banks.

Below we describe the quantity of notes issued, in equilibrium. Prior to doing so, we illustrate some possibilities with respect to equilibrium dynamics.

Dynamical Equilibria: Case 1, $\rho=1$ (agents have logarithmic utility)

In this case, if $e_{t+1}<1$ holds, it is easy to verify that (15) reduces to

$\left(15^{\prime \prime}\right)\left[\left(\gamma_{t+1} / \gamma_{t}\right)-\sigma x\right]\left(\gamma_{t}-\pi\right)=0$.

Clearly (15") implies either that $\gamma_{t+1}=\sigma x \gamma_{t}$, which is inconsistent with $e_{t+1}<1$, or $\gamma_{t}=\pi$. Thus any equilibrium of this economy has either $e_{t+1}=1 / \sigma x<1$ and $\gamma_{t}=\pi$, or $e_{t+1}=1$ and $\gamma_{t+1}=\sigma x \gamma_{t}$ for any $t$. This situation is depicted in Figure 2. Obviously there is a steady state equilibrium in which notes are discounted. In addition, for every integer $T>1$ there exists an equilibrium path with

$$
\gamma_{t}=\left\{\begin{array}{l}
\pi(\sigma x)^{t-T} ; 1 \leq t<T \\
\pi ; t \geq T
\end{array}\right.
$$

In other words, there exists a countably infinite set of equilibria, all of which exhibit no discount on notes for $t<T$, and discounted banknotes for $t \geq T$. 
Dynamical Equilibria: Case 2, $\rho<1$

In this case, (16) gives $\gamma_{t+1}$ as an increasing function of $\gamma_{t}$. The locus defined by (16) is depicted in Figure 3. It is easy to verify that this locus passes through the origin.

If $e_{t+1}<1$ holds, then $\gamma_{t+1}$ is given by (16). If $e_{t+1}=1$ holds, then $\gamma_{t+1}=\sigma x \gamma_{t}$. Some possible dynamical equilibria are depicted in Figures 3.a, 3.b, and 3.c. First, clearly there is a steady state equilibrium in which notes are discounted. Second, as depicted in Figure 3.a, there is a continuum of nonstationary equilibria with $\gamma_{t} \downarrow 0$. Notes are discounted at all dates. Third, as depicted in Figure 3.b, there is a countable infinity of equilibria, parameterized by the integer $T>$ 1 , such that

$$
\gamma_{t}=\left\{\begin{array}{l}
\gamma^{*}(\sigma x)^{t-T} ; 1 \leq t<T \\
\gamma^{*} ; t \geq T
\end{array}\right.
$$

Notes circulate at face value for $t<T$; thereafter, they circulate at a discount.

A particularly interesting possibility is depicted in Figure 3.c. If $\gamma_{t} \leq \gamma^{*} / \sigma x$ holds, then there is an equilibrium in which $e_{t+1}=1$ and $\gamma_{t+1}=\sigma x \gamma_{t}$. There is also an equilibrium in which $e_{t+1}<1$ and $\gamma_{t+1}$ is given by (16). In particular, equilibria are defined by

$$
\gamma_{t+1} \in\left\{\sigma x \gamma_{t}, \sigma x \gamma_{t}\left[\left(\frac{1-\pi}{\pi}\right)\left(\frac{\gamma_{t}}{1-\gamma_{t}}\right)\right]^{\frac{\rho}{1-\rho}}\right\}
$$

whenever $\gamma_{t} \leq \gamma^{*} / \sigma x$. Thus equilibrium paths satisfy a law of motion with two branches defined 
on a common domain. ${ }^{24}$ As illustrated in Figure 3.c, a possible consequence is that there are equilibria exhibiting oscillations of either finite or infinite duration. In fact, Figure 3.c depicts a three period cycle consisting of two periods where notes circulate at face value, followed by a period in which notes circulate at a discount and the reserve-deposit ratio declines. This kind of equilibrium is of more than simply academic interest. Every third period reserve-deposit ratios fall, notes are discounted, and the nominal interest rate rises. This situation is reminiscent of several features of antebellum and postbellum banking panics. After the panic is over, notes cease to be discounted, and the reserve-deposit ratio rises. This increase in reserves following a panic is typically observed in historical episodes.

When $\rho<1$ holds, there is in fact a large number of such equilibrium cycles, all of which display the "panic-like" features we have described. The following proposition states a formal result.

Proposition 4. Let $m \geq 1$ and $n \geq 1$ be integers. Then for every pair $(m, n)$ there is an equilibrium where the economy spends $m$ periods with $I_{t}=1=e_{t+1}$, followed by $n$ periods with $I_{t}>1>$ $e_{t+1}$, followed by $m$ periods with $I_{t}=1=e_{t+1}$, and so on.

Proposition 4 is proved in Appendix D. As the proposition indicates, infrequent panics that result in long periods where notes are heavily discounted are quite possible. Such lengthy periods of deep note discounting were quite common in antebellum panics in the U.S.

\footnotetext{
${ }^{24}$ See Azariadis and Smith (1998) for another economy with this feature.
} 
Dynamical Equilibria: Case 3, $\rho>1$

In this case, (16) gives $\gamma_{t+1}$ as a decreasing function of $\gamma_{t}$, and defines a locus as depicted in Figure 4. Clearly the locus defined by $(16)$ passes through the point $(1,0)$. Moreover, this locus intersects the ray $\gamma_{t+1}=\sigma x \gamma_{t}$ at $\gamma_{t}=\pi$. Obviously $\gamma^{*}>\pi$ holds.

For $\gamma_{t}<\pi, \gamma_{t+1}=\sigma x \gamma_{t}$. In particular, satisfaction of (16) would imply negative nominal interest rates. Similarly, for $\gamma_{t}>\pi, \gamma_{t+1}$ must be given by (16). Thus the indeterminacies present in Cases 1 and 2 cannot be observed if $\rho>1$ obtains.

However, it is evident from an inspection of Figure 4 that very complex dynamics are possible when $\rho>1$. Indeed, if $\pi \sigma x>1$ holds, there will be a large number of periodic equilibria. Such equilibria will be similar to those analyzed in Section 7 .

\section{Banknote Issues}

We now turn our attention to describing the quantity of banknotes issued along any equilibrium path. Equation (3), along with the definition of $\gamma_{t}$, implies that the ratio of banknotes issued to deposits, $b_{t} / w$, satisfies

$$
b_{t} / w=\left(1-\gamma_{t}\right) x p_{t+1} / p_{t}+\alpha_{t} \gamma_{t}-(1-\pi) x\left(p_{t+1} / p_{t}\right) /\left[1-\pi+\pi e_{t+1}{ }^{(1-\rho) / \rho}\right] ; t \geq 1
$$

where we have used the fact that $d_{t}^{n}=x /\left[1-\pi+\pi e_{t+1}{ }^{(1-\rho) / \rho}\right]$. (18) describes the evolution of banknote issues very generally. We next consider what happens when banknotes circulate at par (at a discount).

If banknotes circulate at par at $t+1\left(e_{t+1}=1\right)$, then we have $x p_{t+1} / p_{t}=1$. It follows that $b_{t} / w=\pi-\gamma_{t}\left(1-\alpha_{t}\right)$. Since $\alpha_{t}$ is undetermined at $t$, the ratio of banknote issues to deposits can lie anywhere in the interval $[0, \pi]$. Intuitively, when their own notes are not discounted, banks are 
indifferent between paying depositors out of reserves or with banknotes. It follows that the quantity of banknotes issued - and the quantity of reserves carried between $t$ and $t+1$-are indeterminate, although, of course, their sum is not. In principle, then, banknote issues can be quite large when banknotes are not discounted.

When notes are discounted at $t+1\left(e_{t+1}<1\right)$, then $\alpha_{t}=0$ and $e_{t+1}=p_{t} / x p_{t+1}=\gamma_{t+1} / \sigma x \gamma_{t}$ must obtain. Using these facts in (18), it is immediate that, if $e_{t+1}<1$ holds,

$$
b_{t} / w=\left[\sigma x \gamma_{t}\left(1-\gamma_{t}\right) / \gamma_{t+1}\right]-(1-\pi)\left(\sigma x \gamma_{t} / \gamma_{t+1}\right) /\left[1-\pi+\pi\left(\gamma_{t+1} / \sigma x \gamma_{t}\right)^{(1-\rho) / \rho}\right] .
$$

The following result is proved in Appendix E.

PROPOSITION 5. If $e_{t+1}<1$, then $b_{t}=0$ holds.

Proposition 5 states a strong result: when banknotes are discounted, the discount is sufficient to deter banks from issuing them altogether. Moreover, since $e_{t+1}<1$ must hold in a steady state, steady state equilibria have the property that no private banknotes are issued. Of course notes can be issued in positive quantities at any date where discounts on them are absent. We now explore the implications of this observation in the context of our examples.

Case 1. As we have previously observed, in this case there is a countable infinity of equilibria in which $e_{t+1}=1 \forall t \leq T-1$, and in which $e_{t+1}<1 \forall t \geq T$. At all dates prior to $T$, positive note issues can be observed. Private banknote issues will disappear when the economy attains a steady state.

Case 2. In this case, as we have noted, there are equilibrium paths such that the economy never converges to the steady state. Thus notes can be issued in positive quantities at an infinite number of dates. They will not be issued, of course, in periods where notes are discounted. 
Recall that equilibria where $e_{t+1}=1$ for $m$ periods, followed by $n$ periods with $e_{t+1}<1$, and so on, have several features that we associate with recurrent bank panics: periodically notes circulate at a discount, interest rates are high, and reserve-deposit ratios are low. Interestingly, Proposition 5 indicates that during these panic-like episodes, banknotes will not be issued.

This is true despite the fact that in a panic liquidity is scarce, and banks can create liquidity by printing notes. And, indeed, we will see that in antebellum panics, note issues by banks did decline. In fact, in the panic of 1837 in Pennsylvania—which had no Suffolk Banking System-net note issues by an important set of banks were quite small, as we will demonstrate.

\section{Private Note Issue With a Suffolk Banking System in Place}

As we have previously observed, the Suffolk Bank (a) accepted the notes of member banks at par, (b) engaged in net clearing of notes, (c) required member banks to hold noninterest bearing deposits consisting of a "permanent deposit" based on the member bank's capital, ${ }^{25}$ and a "clearing balance" based on notes cleared, and (d) made loans to members of the system. We now want to introduce an institution that performs these functions into the environment described in Sections 2-5. We believe that, given the environment, the following modification is a natural one.

Imagine now that there are three rather than two locations. No one lives in location 3 and there is no goods market trade or consumption that occurs there. However, location 3 is "in between" locations 1 and 2, and all relocated agents can stop there temporarily while in transit from their location of origin to their destination. This set-up is depicted in Figure 5.

\footnotetext{
${ }^{25}$ During the period in which the Suffolk Banking System was in operation, bank capital was typically specified by a bank's charter, and did not vary to any significant degree. Thus, for any member bank, it is not unreasonable to regard the permanent deposit as a constant amount.
} 
Suppose that an entity (the Suffolk Bank) establishes an office in location 3. At each date, agents from locations 1 and 2 arrive there carrying notes issued by banks in their original location. These can be taken to Suffolk and exchanged for notes issued by banks in their destination location. ${ }^{26}$ Since there are equal numbers of agents traveling in each direction, and since locations are symmetric, this note market clears when notes of all banks exchange at par. Moreover, when agents arrive at their destination, they are carrying notes issued by local banks, which can always be redeemed at par. Hence notes never circulate at a discount.

We further assume that Suffolk has an office in locations 1 and 2. This office takes deposits from, and makes loans to members of the Suffolk Banking System. For the purposes of our analysis, and for the present, we assume that all banks are members of the Suffolk Banking System. $^{27}$

Based on historical verisimilitude, Suffolk requires system members to keep a deposit with it. These deposits do not pay (nominal) interest. Let $q_{t}$ be the real value (per depositor) of the deposit held with Suffolk by a representative bank at $t$. In addition, Suffolk allows system members to borrow from it. Let $\ell_{t}$ be the real value of loans from Suffolk to a representative member bank at $t$ (per depositor). We assume that Suffolk charges an exogenously selected gross real rate of interest $R<x$ on these loans. Since $R<x$ holds, clearly Suffolk must ration the loans it makes at $t$. We therefore assume that Suffolk sets a ceiling $\bar{\ell}$ on the loans it will make to any member bank, so that $\ell_{t} \leq \bar{\ell}$ must hold. Note that among the "services" Suffolk offers to system members is subsidized credit. Clearly we will also assume that $\sigma R \geq 1$ holds; this as-

\footnotetext{
${ }^{26}$ We could also imagine that they are exchanged for Suffolk's notes.

${ }^{27}$ We describe below conditions under which all banks will voluntarily join the system.
} 
sumption is sufficient to imply that Suffolk charges positive nominal rates of interest on interbank loans.

As before, let $b_{t}$ be the real value of the notes issued by a representative bank at $t$ (per depositor). All of these notes will in some sense be "cleared" by Suffolk. Suffolk requires banks to hold a deposit with it consisting of a "clearing balance" equal to the value of notes cleared $\left(b_{t}\right)$, plus a "permanent deposit." We assume that Suffolk sets a constant value $\varepsilon \geq 0$ for the permanent deposit. Then

$$
q_{t} \geq b_{t}+\varepsilon ; t \geq 1
$$

must hold.

At date $t$, then, Suffolk receives (in each location) deposits of $q_{t}$ and makes loans of $\ell_{t}$. The difference, $q_{t}-\ell_{t}$, is invested (stored) by Suffolk. Hence Suffolk's portfolio income at $t+1$ is

$$
x\left(q_{t}-\ell_{t}\right)+R \ell_{t}=x q_{t}-(x-R) \ell_{t}
$$

We assume that Suffolk earns zero profits. ${ }^{28}$ Hence the real value of payments to its own depositors (other banks) by Suffolk at $t+1$ - which is given by $q_{t}\left(p_{t} / p_{t+1}\right)$ - must satisfy

$$
\left[x-\left(p_{t} / p_{t+1}\right)\right] q_{t}=(x-R) \ell_{t}=(x-R) \bar{\ell} ; t \geq 1
$$

where the last equality anticipates the result that, in equilibrium, $\ell_{t}=\bar{\ell}$ must hold.

By way of comment, we note that we have modeled Suffolk's behavior as purely exogenous. As a matter of history, Suffolk was a monopolist in the provision of interbank services for much of its existence. ${ }^{29}$ To “endogenize" Suffolk's behavior in an historically reasonable way,

\footnotetext{
${ }^{28}$ This assumption is hugely at variance with historical reality. See Rolnick, Smith, and Weber (1998).

${ }^{29}$ See Redlich (1947) or Rolnick, Smith, and Weber (1998).
} 
we would have to model it as a monopolist, and deal with how its profit distribution affectedand was affected by — the determination of a full general equilibrium. This is clearly a difficult task, and we do not undertake it here.

We now examine the optimal behavior of banks belonging to the system we have just described.

\section{A. The Behavior of Member Banks}

As before, we model banks as choosing a vector of gross deposit returns, $\left(d_{t}^{m}, d_{t}^{n}\right)$, a level of reserves (per depositor), $m_{t}$, and a level of storage, $k_{t}$. Banks also issue notes with a real value $b_{t}$, and these notes are never discounted. In addition, banks make deposits $q_{t}$ with Suffolk and borrow $\ell_{t}$ from it. Finally, banks carry a fraction $\alpha_{t}$ of their reserves between $t$ and $t+1$. Given Suffolk's behavior, then, members of the system face the following constraints. First, reserve holdings plus storage cannot exceed deposits plus the net amount borrowed from Suffolk:

$$
m_{t}+k_{t} \leq w+\ell_{t}-q_{t} ; t \geq 1
$$

Second, deposits with Suffolk must satisfy (20). Third, the real value of payments to relocated agents cannot exceed the future purchasing power of the notes and currency they withdraw:

$$
\pi d_{t}^{m} w \leq\left(1-\alpha_{t}\right) m_{t}\left(p_{t} / p_{t+1}\right)+b_{t}\left(p_{t} / p_{t+1}\right) ; t \geq 1
$$

Fourth, payments to nonrelocated agents cannot exceed the income from the bank's investments (storage), plus the real value of its unliquidated reserves, plus the real value of its deposits at Suffolk, less its loan repayments to Suffolk, less its note redemptions. Thus

$$
(1-\pi) d_{t}^{n} w \leq \alpha_{t} m_{t}\left(p_{t} / p_{t+1}\right)+x k_{t}+q_{t}\left(p_{t} / p_{t+1}\right)-R \ell_{t}-b_{t}\left(p_{t} / p_{t+1}\right) ; t \geq 1
$$


Notice that (24) reflects (a) that Suffolk deposits pay no nominal interest, and (b) that all notes are redeemed in one period, as previously. Finally, of course, $0 \leq \ell_{t} \leq \bar{\ell}$ must hold.

As before, we seek a Nash equilibrium in which, given the choices of other banks, no bank will perceive an incentive to alter its own actions. And, as before, in a Nash equilibrium each active bank must choose $d_{t}^{m}, d_{t}^{n}, m_{t}, k_{t}, b_{t}, \alpha_{t}, q_{t}$, and $\ell_{t}$ to solve the problem

$$
\max \pi\left(d_{t}^{m} w\right)^{1-\rho} /(1-\rho)+(1-\pi)\left(d_{t}^{n} w\right)^{1-\rho} /(1-\rho)
$$

subject to (20), (22), (23), (24), and $\ell_{t} \leq \bar{\ell}$. We now make several observations about the solution to this problem.

First, since $R<x$, clearly $\ell_{t}=\bar{\ell}$ will hold at an optimum (Suffolk Banking System members will borrow as much as possible at subsidized rates). Second, if nominal rates of interest on investments are positive $\left(I_{t} \equiv x p_{t+1} / p_{t}>1\right)$, the constraint (20) must be binding: system members will hold the smallest possible noninterest bearing deposit. With these observations, we may transform the problem of a representative bank as follows. Substitute $\ell_{t}=\bar{\ell}, q_{t}=b_{t}+\varepsilon$, and (22) at equality into (24) and solve for $x b_{t}$ to obtain

$$
x b_{t}=\alpha_{t} m_{t}\left(p_{t} / p_{t+1}\right)+(x-R) \bar{\ell}-\varepsilon\left[x-\left(p_{t} / p_{t+1}\right)\right]+x\left(w-m_{t}\right)-(1-\pi) d_{t}^{n} w ; t \geq 1 .
$$

Then use (25) in (23):

$$
\begin{aligned}
\pi d_{t}^{m} w+(1-\pi) d_{t}^{n} w\left(1 / I_{t}\right)= & m_{t}\left(p_{t} / p_{t+1}\right)\left[\left(1-I_{t}\right) / I_{t}\right] \alpha_{t}+(x-R) \bar{\ell} / I_{t}-\left(\varepsilon / I_{t}\right)\left[x-\left(p_{t} / p_{t+1}\right)\right] \\
& +w\left(p_{t} / p_{t+1}\right) ; t \geq 1
\end{aligned}
$$

The bank can then be viewed as maximizing the expected utility of a representative depositor subject to (26), $0 \leq m_{t}$, and $0 \leq \alpha_{t} \leq 1$.

Define the value $y_{t}$ by 


$$
y_{t} \equiv\left(p_{t} / p_{t+1}\right)+\left[(x-R) / I_{t}\right](\bar{\ell} / w)-(\varepsilon / w)\left(p_{t} / p_{t+1}\right)\left(I_{t}-1\right) / I_{t} .
$$

Then $w y_{t}$ is the discounted present value of the bank's deposits, plus the value of the subsidized lending it receives from Suffolk, less the loss attributable to being forced to hold interest-free deposits at Suffolk. With this definition, we are prepared to state the following result.

Proposition 6. Suppose that $I_{t} \equiv x\left(p_{t+1} / p_{t}\right)>1$ holds. Then the solution to the bank's problem sets $\alpha_{t}=0$. In addition,

$$
\begin{aligned}
& d_{t}^{m}=\left(1 / I_{t}\right)^{1 / \rho} d_{t}^{n} ; t \geq 1 \\
& d_{t}^{n}=y_{t} I_{t}^{1 / \rho} /\left[\pi+(1-\pi) I_{t}^{(1-\rho) / \rho}\right] ; t \geq 1 .
\end{aligned}
$$

The proof of Proposition 6 appears in Appendix F.

\section{General Equilibrium With a Suffolk Banking System}

As before, let $\gamma_{t} \equiv m_{t} / w$ be the reserve-deposit ratio of a representative bank at $t$. Then, as previously, money market clearing requires that (10) hold. It is an immediate implication that $p_{t} / p_{t+1} \equiv \gamma_{t+1} / \sigma \gamma_{t}$

In addition, in each location, "sources" of goods and "uses" of goods must be equal at each date. "Sources" of goods are endowments plus the proceeds of the previous period's storage plus net transfers from Suffolk. Uses of goods are consumption by relocated (nonrelocated) old agents, $\pi d_{t}^{m} w\left((1-\pi) d_{t}^{n} w\right)$, plus government expenditures, $[(\sigma-1) / \sigma] m_{t+1}$, plus current in- 
vestments in storage. Since net transfers from Suffolk are $\left(p_{t} / p_{t+1}\right) q_{t}+\bar{\ell}-q_{t+1}-R \bar{\ell}$ at $t+1$, "sources" of goods equal "uses" of goods if ${ }^{30}$

$$
\left[\pi d_{t}^{m}+(1-\pi) d_{t}^{n}\right] w+[(\sigma-1) / \sigma] m_{t+1}=w+x k_{t}-k_{t+1}-q_{t+1}+\bar{\ell}-R \bar{\ell}+\left(p_{t} / p_{t+1}\right) q_{t} ; t \geq 1
$$

Using (21) and (22) in (30), the goods market clears in each location if

$$
\pi d_{t}^{m}+(1-\pi) d_{t}^{n}=(1 / \sigma) \gamma_{t+1}+x\left(1-\gamma_{t}\right) ; t \geq 1
$$

Finally, (28) and (29) imply that (31) has the equivalent representation

$$
\gamma_{t+1}+\sigma x\left(1-\gamma_{t}\right)=\sigma y_{t}\left\{\left[\pi+(1-\pi) I_{t}^{1 / \rho}\right] /\left[\pi+(1-\pi) I_{t}^{(1-\rho) / \rho}\right]\right\} ; t \geq 1 .
$$

We now wish to write $\left(31^{\prime}\right)$ entirely in terms of $\gamma_{t}, \gamma_{t+1}$, and exogenous variables. To do so, recall that $I_{t} \equiv x p_{t+1} / p_{t}$. Then

$$
\sigma y_{t} \equiv\left(\sigma x / I_{t}\right)\left\{1+[(x-R) / x](\bar{\ell} / w)-(\varepsilon / w)\left[\left(I_{t}-1\right) / I_{t}\right]\right.
$$

holds. Using (32) and $I_{t} \equiv x p_{t+1} / p_{t} \equiv \sigma x \gamma_{t} / \gamma_{t+1}$ in (31) we obtain the following equilibrium law of motion for $\gamma_{t}$ :

$$
\left[\gamma_{t+1}+\sigma x\left(1-\gamma_{t}\right)\right] / f\left(\gamma_{t+1} / \sigma x \gamma_{t}\right)=1+[(x-R) / x](\bar{\ell} / w)-(\varepsilon / w)\left[1-\left(\gamma_{t+1} / \sigma x \gamma_{t}\right)\right] ; t \geq 1
$$

where, as before,

$$
f\left(\gamma_{t+1} / \sigma x \gamma_{t}\right) \equiv \sigma x\left[(1-\pi)+\pi\left(\gamma_{t+1} / \sigma x \gamma_{t}\right)^{1 / \rho}\right] /\left[(1-\pi)+\pi\left(\gamma_{t+1} / \sigma x \gamma_{t}\right)^{(1-\rho) / \rho}\right]
$$

Prior to analyzing dynamics, we begin with a description of steady state equilibria.

${ }^{30} \mathrm{At} t=1$ goods market clearing is implied by money market clearing. It is then easy to verify that $\gamma_{1}$ is a free initial condition. 


\section{A. Steady State Equilibria}

When $\gamma_{t+1}=\gamma_{t}=\gamma_{s}^{*}$ (the subscript s denotes the presence of a Suffolk Banking System) equation (33) reduces to

$$
\frac{\sigma x-(\sigma x-1) \gamma_{s}^{*}}{f(1 / \sigma x)}=1+[(x-R) / x](\bar{\ell} / w)-(\varepsilon / w)[(\sigma x-1) / \sigma x]
$$

We then have the following result.

PROPOSITION 7. (a) A steady state equilibrium with $\gamma_{s}^{*} \in(0,1)$ exists if

$$
\sigma x / f(1 / \sigma x)>1+[(x-R) / x](\bar{\ell} / w)-(\varepsilon / w)[(\sigma x-1) / \sigma x] \geq 1
$$

(b) $\quad \gamma_{s}^{*}<\gamma^{*}$ holds if

$$
[(x-R) / x](\bar{\ell} / w)>(\varepsilon / w)[(\sigma x-1) / \sigma x]
$$

Proposition 7 is proved in Appendix G. Part (a) of the proposition asserts that a monetary steady state with positive storage exists if (37) holds, and if $[(x-R) / x](\bar{\ell} / w)-(\varepsilon / w)[(\sigma x-1) / \sigma x]$ is not too large. The condition (37) is equivalent to $\left(37^{\prime}\right) \quad \bar{\ell}>\varepsilon(I-1) /(I-\sigma R)$.

In particular, it requires that — in a steady state-Suffolk's lending to member banks is not too small relative to the permanent deposit it requires those banks to hold. The necessary magnitude of $\bar{\ell} / \varepsilon$ depends on $I-\sigma R \equiv \sigma(x-R)$, the implied subsidy on these loans. Part (b) of the proposition states that, if (37) holds, the steady state reserve-deposit ratio is smaller in the presence of Suffolk than it is in Suffolk's absence. If the direction of the inequality in (37) is reversed, the presence of a Suffolk Banking System will raise the reserve-deposit ratio. Since some evidence suggests (Calomiris and Kahn 1996 and Section 9 below) that the reserve-deposit ratio for Suf- 
folk Banking System members was low compared to the rest of U.S. banks at the time, we will henceforth assume that (37) holds. Obviously we will also assume that (36) holds as well, so that the desired steady state equilibrium exists.

In Section 7 we undertake a comparison of steady state welfare in the presence and the absence of a Suffolk Banking System. Prior to doing so, however, we give some consideration to equilibrium dynamics.

\section{B. Dynamical Equilibria}

For arbitrary values of $\rho$, a very rich set of equilibrium dynamics is possible. To simplify matters we henceforth focus on the case $\rho=1$ (logarithmic utility). This constituted Case 1 in Section 5. As we demonstrated there, in the absence of a Suffolk Banking System, the economy must approach the unique steady state when $\rho=1$. Moreover, any economic fluctuations are impossible along dynamical equilibrium paths. We will see that the presence of a Suffolk Banking System dramatically alters this situation.

To begin, we observe that there is no equilibrium with $I_{t}=1$ for any $t$, and in which Suffolk operates. To see this it suffices to observe that $I_{t}=1$ implies that $x=p_{t} / p_{t+1}$. Hence, as is clear from (21), Suffolk cannot earn nonnegative profits. Hence we restrict attention to equilibrium paths with $I_{t}>1 \forall t \geq 1$.

When $I_{t}>1$ holds at all dates, equation (33) governs equilibrium dynamics. In order to simplify this equation further, we henceforth assume that $\varepsilon=0$ (Suffolk requires no permanent deposit). When $\varepsilon=0$, and when $\rho=1$, it is easy to verify that equation (33) simplifies to

$$
\gamma_{t+1}=\sigma x \gamma_{t}\left[1-\lambda(1-\pi)-\gamma_{t}\right] /\left(\lambda \pi-\gamma_{t}\right) \equiv Q\left(\gamma_{t}\right) ; t \geq 1
$$

where 


$$
\lambda \equiv 1+[(\mathrm{x}-R) / x](\bar{\ell} / w) .
$$

If Suffolk engages in subsidized lending to member banks $(x>R$ and $\bar{\ell}>0)$, clearly $\lambda>1$ holds. Obviously then (37) is satisfied. Since in this case $\gamma_{s}^{*}=\lambda \pi-\sigma x(\lambda-1) /(\sigma x-1)$, the condition (36) reduces to $\left(36^{\prime}\right)(\sigma x-1) \lambda \pi>(\lambda-1) \sigma x$.

Since $(\lambda-1)$ is the net subsidy provided by Suffolk (per unit deposited), $\left(36^{\prime}\right)$ again asserts that this subsidy cannot be too large.

Under the assumption that $\left(36^{\prime}\right)$ holds, it is possible to state the following properties of the function $Q$.

Proposition 8. (a) The function $Q$ satisfies

$$
Q(0)=0=Q[1-\lambda(1-\pi)]
$$

and

$$
Q(\gamma)>0 \forall \gamma \in(0,[1-\lambda(1-\pi)])
$$

(b) $\quad Q^{\prime}(\gamma) \geq 0$ holds if $\gamma \in[0, \tilde{\gamma}]$ and $Q^{\prime}(\gamma)<0$ holds if $\gamma \in(\tilde{\gamma}, 1]$, where

$$
\tilde{\gamma} \equiv \lambda \pi-[\lambda \pi(\lambda-1)]^{1 / 2}<1-\lambda(1-\pi)
$$

The proof of Proposition 8 is given in Appendix H. The proposition allows us to determine that the equilibrium law of motion for $\gamma_{t}$ can have either the configuration depicted in Figure 6.a or that in Figure 6.b. ${ }^{31}$ It will be useful to know when the configuration represented in

\footnotetext{
${ }^{31}$ Figure 6.b is drawn under the assumption that equation (40) is satisfied (see Proposition 9). However, much of the discussion that follows applies equally to the case where (40) fails to hold.
} 
Figure 6.b obtains. We now turn our attention to this issue.

If $Q(\tilde{\gamma})>\widetilde{\gamma}$ holds, then it is apparent that $\gamma_{s}^{*}>\widetilde{\gamma}$, and that $Q^{\prime}\left(\gamma_{s}^{*}\right)<0$ is satisfied. We now state the following result.

Lemma 2. $Q(\tilde{\gamma})>\widetilde{\gamma}$ holds iff

$$
[(\sigma x-1) / \sigma x]^{2}>(\lambda-1) / \lambda \pi
$$

Lemma 2 is proved in Appendix I. The lemma asserts that the equilibrium law of motion for $\gamma_{t}$ has the configuration depicted in Figure 6.b iff (39) is satisfied. Clearly (39) is satisfied either if (a) the net loan subsidy provided by Suffolk is sufficiently small, or (b) $\sigma x$ (the steady state gross nominal rate of interest) is sufficiently large.

Two more important questions remain. One is, when does $Q(\tilde{\gamma})>1-\lambda(1-\pi)$ hold? The answer to this question has strong implications for the existence of equilibrium cycles under a Suffolk Banking System. The second question is, when is the nontrivial steady state equilibrium asymptotically stable? We next address these issues.

If $Q(\tilde{\gamma})>1-\lambda(1-\pi)$ holds (as depicted in Figure 6.b), then there exist equilibrium trajectories in which $\gamma_{1}>0$ holds, and in which $\lim \gamma_{t}=0$ (see Figure 6.b). Such trajectories are called homoclimic orbits (Devaney 1989; p. 124). ${ }^{32}$ When such orbits exist (and satisfy one technical condition), then in every neighborhood of the origin there exist infinitely many distinct periodic points. In particular, there is an equilibrium in which $\gamma_{t}$ evolves according to a $2^{j}$ period cycle for every integer $j$. In short, endogenously generated volatility that does not damp-

\footnotetext{
${ }^{32}$ These orbits are also nondegenerate (Devaney, p. 124).
} 
en asymptotically is quite possible. With $\rho=1$, such volatility was impossible in the absence of a Suffolk Banking System.

Moreover, some such orbits will have the feature that, within every cycle, there is one precipitous decline in the reserve-deposit ratio. Such declines will have many of the features of a bank panic: reserves drop, and the nominal rate of interest rises - in both cases possibly by a large amount. This observation makes clear that the presence of a Suffolk-like system need provide no panacea for the phenomenon of bank panics.

For this reason, we would like to know when $\mathrm{Q}(\tilde{\gamma})>1-\lambda(1-\pi)$ holds. The following result contains the answer.

PROPOSITION 9. $Q(\tilde{\gamma})>1-\lambda(1-\pi)$ holds iff

$$
[(\sigma x-1) /(\sigma x+1)]^{2}>(\lambda-1) / \lambda \pi
$$

Proposition 9 is proved in Appendix J. When (40) holds, undamped oscillation accompanied by periodic panic-like phenomena can readily be observed under a Suffolk Banking System.

Finally, when is the steady state with $\gamma_{s}^{*}>0$ asymptotically stable? The following proposition contains the relevant result.

Proposition 10. $Q^{\prime}\left(\gamma_{s}^{*}\right)>-1$ holds iff

$$
\lambda \pi(3 \sigma x-1)>\sigma x(\sigma x+1)[1-\lambda(1-\pi)] .
$$

The proof of Proposition 10 is given in Appendix K. The proposition implies that the monetary steady state in the presence of a Suffolk Banking System is asymptotically stable if $\sigma x$ is not too large. 
We observe that when the equilibrium law of motion for $\gamma_{t}$ has the configuration depicted in Figure 6.b, the steady state $\gamma_{s}^{*}>0$ can be asymptotically stable. And, the steady state $\gamma_{s}^{*}>0$ must be asymptotically stable if the equilibrium law of motion has the configuration depicted in Figure 6.a. Thus, if Figure 6.a obtains - or if Figure 6.b obtains and (41) holds—we have an important implication. Monetary equilibria are indeterminate, and a continuum of nonstationary monetary equilibria exist that do not exhibit a hyperinflation. And, if (39) holds along with (41), any equilibrium path converging to the monetary steady state must exhibit endogenously generated volatility en route. ${ }^{33}$

To summarize, we have focused on the case $\rho=1$. In the absence of a Suffolk Banking System, setting $\rho=1$ rules out any equilibria displaying endogenous volatility (although it does not rule out indeterminacies). In the presence of a Suffolk Banking System, endogenous volatility will be observed if $\sigma x$ is sufficiently large, or if $\lambda-1$ is sufficiently small. ${ }^{34}$ Moreover, cycles of long periodicity are quite possible. These observations have many corollaries. For instance, Suffolk-like systems will be particularly open to endogenous volatility in economies with rapid rates of growth in the outside money stock. They will similarly be open to endogenous volatility if the operator of the system subsidizes loans in only a small way. And, they will be open to indeterminacies for a wide range of money growth rates and for a wide range of potential loan subsidies.

\footnotetext{
${ }^{33}$ Unless, of course, the economy has $\gamma_{1}=\gamma_{s}^{*}$.

${ }^{34}$ Again, unless $\gamma_{1}=\gamma_{s}^{*}$.
} 


\section{Steady State Welfare Under the Two Arrangements}

\section{A. A Welfare Ranking}

In a steady state equilibrium, $I=\sigma x$ obtains under both possible regimes. In addition, whether or not a Suffolk Banking System is present, $d_{t}^{m}=\left(1 / I_{t}\right)^{1 / \rho} d_{t}^{n}$ holds in a steady state. Thus we can evaluate the ex ante expected utility of young agents across steady states simply by comparing the values of $d_{t}^{n}$ with and without a Suffolk Banking System.

When no Suffolk Banking System is in place, the steady state value of $d^{n}$ is given by

$$
d^{n}=x /\left[(1-\pi)+\pi I^{(\rho-1) / \rho}\right] .
$$

When a Suffolk Banking System operates, the steady state value of $d^{n}$ satisfies

$$
d^{n}=y I /\left[(1-\pi)+\pi I^{(\rho-1) / \rho}\right]
$$

Thus, comparing steady states, young agents prefer that a Suffolk Banking System operate iff

$$
y I=\sigma x y \geq x
$$

or, equivalently, iff $\sigma y \geq 1$. Using equation (32) and $I=\sigma x$, it is apparent that (42) holds iff (37) obtains. We then have the following result.

Proposition 11. The introduction of a Suffolk Banking System raises the steady state welfare of young agents iff it reduces the steady state value of the reserve-deposit ratio.

Proposition 11 indicates that the Suffolk lending program benefits young agents, in a steady state, because it induces the economy to economize on its holdings of low return cash reserves.

However, if the economy is in a steady state from the initial date, a reduction in the reserve-deposit ratio raises the time 1 price level (as well as all subsequent price levels). This re- 
duces the value of the outside money held by the initial old agents. Thus they prefer that the Suffolk Banking System not operate if it reduces the reserve-deposit ratio.

To summarize, when one compares steady state equilibria, the initial old and all young agents will have opposing preferences with respect to the introduction of a Suffolk Banking System. Of course, as we have noted, a steady state need not be attained under either arrangement. A welfare comparison of nonstationary equilibria will almost certainly result in an even less clear cut Pareto comparison of the two regimes.

\section{B. Voluntary Membership in the Suffolk System}

Up to this point we have simply assumed that all banks are members of the Suffolk System. We now state a condition under which banks given a choice will voluntarily join such a system. This condition is closely related to the condition implying that the presence of the system raises the steady state welfare of young agents.

Suppose now that the Suffolk-style system we have described is in place. In addition, other banks are free either to join, or not to join this system. Under what circumstances will all banks opt to become system members?

If $I_{t}>1$ holds, and if a bank does not join the Suffolk system at $t$, we know that it will perceive an arbitrage opportunity unless its notes bear a discount (in the other location) of $e_{t+1} \leq$

$I_{t}^{-1}$. Thus the presence of such a discount on the notes of nonsystem members is a necessary condition for the existence of an equilibrium where the system operates.

Assuming that there is such a discount, then, the problem of banks not belonging to the Suffolk System is identical to that described in Section 4. The problem of banks belonging to the system is obviously identical to that of Section 6. It is then apparent that, since all banks face the 
same rates of return, any bank will voluntarily join the Suffolk System iff $x \leq y_{t} I_{t}$ holds. This condition is readily shown to be equivalent to

$$
(x-R) \bar{\ell} \geq \varepsilon\left(p_{t} / p_{t+1}\right)\left(I_{t}-1\right) .
$$

In a steady state, the satisfaction of (43) is implied by the satisfaction of (37). Thus, if the activities of the Suffolk System raise the steady state welfare of young agents, all banks will choose to join the system voluntarily.

Outside of steady states, of course, (43) imposes a constraint that must be satisfied along dynamical equilibrium paths. This constraint will be nonbinding whenever $\varepsilon \leq(x-R) \bar{\ell} / x$ holds. In other words, if the permanent deposit required as a condition of Suffolk membership is not too large, banks will always utilize their option to join the system.

\section{An Historical Comparison}

In the preceding sections we have presented a simple stylized model of note-issuing banks. In Sections 4 and 5 we considered a banking system in which the absence of centralized clearing arrangements allowed discounts on notes to be observed. In Sections 6 and 7 we analyzed the behavior of an otherwise identical banking system, but in which banks belonged to a centralized clearing arrangement meant to resemble the Suffolk Banking System. We now undertake a comparison of what we believe to be a representative set of Suffolk Banking System members with what we also believe to be a representative set of banks that had no analog of a Suffolk Banking System in place.

The historical Suffolk Banking System extended throughout New England. A large majority, but not all, New England banks were members. Unfortunately, we know of no list of banks that were members of the Suffolk Banking System. Instead, we take the aggregate of 
Massachusetts banks over the period 1825-1860, the period during which the Suffolk Banking System (or a successor) operated, to represent the System. Of course this omits other New England banks that were members of the Suffolk System, and it includes some Massachusetts banks that were not Suffolk Banking System members. ${ }^{35}$ However, on the whole, we do not believe that there are strong reasons to think that this introduces any particular biases: some large Providence banks are omitted from the sample as are many small Maine, Vermont, and New Hampshire banks. In any event, since data are only available on a state-by-state basis, we do not believe that a superior procedure is currently available.

Another state for which very rich banking data are available at frequent intervals is Pennsylvania. Of course Pennsylvania had no analog of a Suffolk Banking System in place, but it did have an even larger and more important financial center than Boston. And, to complicate matters, until 1836 Philadelphia was the headquarters of the Second Bank of the United States, the nation's sole federally chartered — and its largest—bank. While the Second Bank was heavily engaged in interbank payments, it did not engage in net clearing or necessarily accept other banks' notes at par. ${ }^{36}$ Thus it did not perform the functions of the Suffolk Banking System.

In this section we examine the behavior of Pennsylvania banks - not including the Second Bank or its successor-from 1825-1860. In 1836 the Second Bank lost its federal charter: it operated under a state charter from that time until 1841 when it became defunct. Since clearly the presence of the Second Bank renders a Massachusetts-Pennsylvania comparison less "clean," we will also compare banking system performance over the period 1841-1860. Thus we take

\footnotetext{
${ }^{35}$ Some prominent Massachusetts banks did not belong to the Suffolk Banking System; for instance, the Massachusetts Bank of Boston.

${ }^{36}$ Indeed, the Second Bank did not always accept notes issued by its own branches at par. While the Second Bank had branches in New England, its operations there were small relative to those in Philadelphia.
} 
Massachusetts banks to be representative of members of the Suffolk Banking System, and Pennsylvania banks to be representative of the behavior of banks with nearby access to a large financial center, but without a Suffolk-style system. ${ }^{37}$

Our empirical comparison of Massachusetts and Pennsylvania banks is motivated by the theoretical analysis of Sections 4-8. Prior to presenting the data, we summarize some of the implications of this analysis.

First, in order to increase welfare, it would have been important that the existence of the Suffolk Banking System induced the banking system as a whole to hold a lower level of unproductive specie reserves than would otherwise have been the case. Second, the analysis states conditions (see Proposition 7) under which we would expect the actions of the Suffolk Bank to lead other banks to economize on specie reserves (at least near a steady state). We will examine these aspects of the data.

The analysis also predicts that in a "panic" (a period of sharply increased nominal interest rates and note discounts), note issue absent a Suffolk Banking System should decline-potentially to zero. Under similar circumstances, aggregate note issues by members of a Suffolk-like system need not decline at all. And, at least near a steady state, the analysis predicts higher note issues by Suffolk Banking System members than would be observed absent a Suffolk Banking System.

With respect to volatility, the model makes no sharp predictions. Absent exogenous shocks, there need be no volatility under either system. And, volatility could potentially be greater in either the presence or the absence of a Suffolk Banking System. However, the analysis

\footnotetext{
${ }^{37}$ We might also note that branching restrictions and other aspects of state regulation seem to have been relatively similar in Massachusetts and Pennsylvania.
} 
does imply that there is no reason to believe that the activities of a Suffolk Banking System can eliminate either endogenously arising volatility or the potential for panic-like phenomena to be observed. And, our examples have illustrated the possibility (when $\rho=1$ ) that the introduction of a Suffolk-like system can create a scope for endogenous volatility where no such scope would otherwise exist. In any case, we will also examine the relative volatility of financial system conditions in Massachusetts and Pennsylvania.

Figure 7.a presents ratios of specie reserves to deposits for Massachusetts and Pennsylvania; Figure 7.b presents ratios of specie reserves to deposits plus capital. ${ }^{38}$ (The shaded areas in Figures 7-10 represent periods of financial panics.) As is apparent, the ratio of specie reserves was almost uniformly lower in Massachusetts. And the mean ratio of specie to deposits in Massachusetts over 1825-1860 (1841-1860) was 0.26 (0.28): in Pennsylvania the mean value of this ratio was $0.39(0.41)$. For the ratios of specie to deposits plus capital the analogous numbers are $0.06(0.07)$ for Massachusetts, and $0.15(0.18)$ for Pennsylvania. Thus membership in the Suffolk Banking System appears to have permitted substantial economization on specie reserves. This would potentially have been quite important from a welfare perspective.

According to Proposition 7—at least near a steady state—this reduction in specie reserves should only have been possible if Suffolk's interbank lending was sufficiently large. In particular, that lending should have exceeded the value of permanent deposits held at Suffolk. ${ }^{39}$

\footnotetext{
${ }^{38}$ Of course the theoretical analysis abstracts from capital. During the period we analyze capital had many of the features of modern deposits: bank directors and other important equity holders could easily borrow against their equity positions, effectively making the analog of a withdrawal. Since bank capital was typically large in the antebellum U.S., we want it to be reflected in the data we present. Therefore, we will typically present bank balance sheet items both as a ratio to deposits, and as a ratio to deposits plus capital.

${ }^{39}$ By how much would depend on the size of the subsidy in Suffolk's interbank lending.
} 
There is no direct data on the value of permanent interbank deposits held with the Suffolk Bank. But we know that, except for certain large Boston banks, members were required to hold permanent deposits equal to 2 percent of their capital. Since we have data on capital (although not exact data on Suffolk Banking System membership), we can readily approximate this component of permanent deposits. In addition, large Boston banks were required to hold a permanent deposit that changed over time, from an initial value of $\$ 30,000$ to a final value of $\$ 5,000$. However, we do not have the schedule of reductions, and hence cannot determine the exact value of permanent deposits at most dates for large Boston system members. We therefore proceed as follows. We approximate permanent deposits at Suffolk as 2 percent of aggregate capital for all Massachusetts banks other than large Boston banks, and then we add $\$ 5,000(\$ 30,000)$ for each large Boston bank to form an estimate of a lower (upper) bound on permanent deposits. ${ }^{40}$

For Suffolk lending, we use its balance sheet category "due from other banks." For most banks this would consist of two items, loans made to other banks and deposits held at other banks. Of course the structure of the Suffolk Banking System obligated system members other than Suffolk itself to hold interbank deposits. We believe that for most Massachusetts banks "due froms" consist primarily of interbank deposits. For Suffolk itself there was no particular reason to hold substantial interbank deposits. We therefore believe that its "due froms" consist largely of loans to other banks.

Suffolk's "due froms," along with our estimated upper and lower bounds on permanent deposits, are plotted in Figure 8. Evidently, from 1833 on Suffolk's lending to other banks ex

\footnotetext{
${ }^{40}$ Of course not all Massachusetts banks were Suffolk Banking System members. But our data omits the capital of system members in Connecticut, Rhode Island, Maine, Vermont, and New Hampshire. Thus we think it is reasonable to take the "lower bound" on permanent deposits as a real lower bound.
} 
ceeded the lower bound on permanent deposits at all but a few dates. Interestingly, 1833 is when the Suffolk Banking System "took off," and it is when Suffolk's correspondent banking activities began to be profitable. ${ }^{41}$ Given that the model predicts this excess of lending over permanent deposits is a requisite condition for banks (and depositors) to experience higher welfare from system membership (at least near a steady state), we believe that this coincidence of events around 1833 was no accident. Similarly, after 1833 "due froms" fell below the lower bound on permanent deposits only in 1853: it was in 1854-55 that strong support for a Suffolk competitor emerged. $^{42}$

Of course the upper bound on permanent deposits typically exceeds Suffolk's interbank lending. Thus we cannot be certain that the condition for specie reserves to be reduced was generally satisfied. But, based on the observations in the previous paragraph, we think there are strong reasons to take the lower bound on permanent deposits more seriously than the upper bound, especially later in the period. And, as these observations indicate, it was unlikely that the implied subsidy provided to Suffolk Banking System members $(\lambda$, in the notation of Section 7$)$ was very large. This is exactly the kind of condition required for endogenous volatility to be possible under a Suffolk-like arrangement.

To get a handle on the relative magnitude of note issues, we proceeded as follows. Almost all banks issued notes. In addition, most banks held some notes issued by other banks ("bills of other banks") as a balance sheet item. To measure net note creation by the banking

\footnotetext{
${ }^{41}$ See Rolnick, Smith, and Weber (1998).

${ }^{42}$ Suffolk's "due froms" are below the lower bound on permanent deposits from 1858 on. At this point, Suffolk had closed down the traditional Suffolk Banking System.
} 
system, we computed the aggregate quantity of notes issued ("notes in circulation"), and subtracted off aggregate holdings of "bills of other banks." The result, which we call "bills in the hands of the public" is plotted for Massachusetts and Pennsylvania in Figures 9.a and 9.b. In the former case, this quantity is divided by deposits; in the latter case by deposits plus capital. As is apparent from Figure 9.a, the ratio of bills in the hands of the public to deposits was higher in Massachusetts than in Pennsylvania: from 1825-1860 (1841-1860) the mean value of this ratio in Massachusetts was $0.84(0.88)$, while in Pennsylvania it was $0.66(0.57)$. When the divisor is capital plus deposits the ratios are far more similar (a mean of about 0.20 for Massachusetts to about 0.25 for Pennsylvania, independent of time period). However, in our view, this largely reflects the fact that bank capital was much greater in Massachusetts than in Pennsylvania (a mean value of $\$ 45.8$ million in the former over $1841-1860$ to $\$ 20.45$ million for the latter). ${ }^{43}$ We think it is reasonable to conclude that, on average, Suffolk Banking System members created more liquidity than members of the Pennsylvania system.

Moreover, as is clear from Figures 9.a and 9.b, this was particularly true in panics. Shortly after the panic of 1837 (during the deep recession of 1839-1843), net note creation by Pennsylvania banks fell to about $\$ 4$ million. Interestingly, this decline in note issues is what the model predicts. Net note issue by Massachusetts banks, in contrast, remained roughly constant during this period. Net note creation in both states attained a minimum during the panic of 1857 (although a minimum well above zero). However, the contraction in net circulation was clearly far more pronounced in Pennsylvania than in Massachusetts.

\footnotetext{
${ }^{43}$ Genay (1995) argues that the state of Pennsylvania followed the policy of seriously restricting the quantity of bank capital.
} 
As the model predicts, then, liquidity creation (net note issue) in a non-Suffolk Banking System contracted dramatically when liquidity was most scarce (during panics). This was not the case for the Suffolk Banking System. However, during more normal times, the Suffolk Banking System did not have the effect of reducing volatility in net note issues. Indeed, over the period 1841-1860, the standard deviation of net note issues (divided by deposits) in Massachusetts was 0.23 . In Pennsylvania it was exactly half that, 0.12 . Thus, as the analysis indicated, there is no reason to expect the existence of a Suffolk Banking System to reduce overall volatility.

Volatility in the ratio of specie reserves to deposits (deposits plus capital) is also apparent in Figure 7.a (7.b) Specie reserves of Pennsylvania banks plummeted during the panic of 1857; while this is not the case for Massachusetts banks. However, in normal times (1841-1860) the volatility of specie reserves to deposits, as measured by its standard deviation, is virtually identical in the two states. Thus again the Suffolk Banking System did not have the effect of reducing overall volatility.

Figures 10.a and 10.b show the ratio of loans to deposits, and of loans to deposits plus capital. As might be expected, lending by Pennsylvania banks declined precipitously during the prolonged difficulties of 1837-1843. Lending declined again, although far less dramatically, in the panic of 1857 . In contrast, lending by Massachusetts banks was relatively high during the 1837-1843 period, although it too declined in the panic of 1857 . But, overall, lending by Massachusetts banks (at least as a ratio to deposits) was far more volatile than that for Pennsylvania banks. Indeed, over 1841-1860 the standard deviation of the loan-to-deposit ratio for Pennsylvania banks was 0.25 . For Massachusetts, it was 0.82 . 
To summarize, banks were far more successful in economizing on specie holdings in Massachusetts than they were in Pennsylvania. And, in Massachusetts, there were not enormous declines in lending or in liquidity creation during panics. Moreover, overall, Massachusetts banks injected more liquidity into the economy than Pennsylvania banks. But this certainly did not mean that there was less volatility in most aspects of banking in Massachusetts than there was in Pennsylvania. All of this is consistent with the theoretical analysis.

Parenthetically, our theoretical analysis considers the banking systems of "closed economies" (and, in particular, there is no interaction with banks elsewhere). Clearly this is not an accurate description even of antebellum banking in the U.S. But, we also believe it is not too bad an overall approximation. Figure 11.a (11.b) plots the difference between the amounts owed to other banks ("due to other banks") and the amounts lent to other banks through interbank loans and deposits ("due from other banks"). In a closed economy these should sum to zero. For Pennsylvania banks the mean value of "due froms" minus "due tos" was -0.01 (with a standard deviation of 0.02). For Massachusetts the mean value is 0.00 (with a standard deviation of 0.02 ). Moreover, as the figures make clear, there is rarely much deviation from an approximately zero net position for each state. This bolsters the case for treating them as "closed economies."

\section{Conclusions}

Current developments in transaction technology have made it feasible to issue the electronic equivalent of private banknotes. And, the current status of regulation apparently allows agents to do this. These observations suggest that it will soon be important to understand the monetaryand the broader economic_-implications of private note issue.

Proponents of the view that private agents can be left to issue currency, or close substitutes for it, in an unrestricted way have often pointed to the Suffolk Banking System as an his- 
torical example of a well-functioning, essentially private monetary system. And, indeed, the Suffolk Banking System succeeded in eliminating note discounts, and it seems to have been able to deal with bank panics more smoothly than these were dealt with elsewhere. However, as we have shown, there is no reason to believe that the presence of a Suffolk Banking System alone can resolve all of the indeterminacies that might arise in its absence. Nor should one expect a Suffolk-style system to provide a guarantee that bank panics cannot occur. And, finally, we have shown that the presence of a Suffolk Banking System can easily enhance, rather than reduce, overall macroeconomic volatility, and the overall volatility of the financial system. On the latter point the data seem to bear us out.

Of course, our analysis has abstracted from many important features of historical—and modern—banking systems. We have, for example, considered only an economy with no aggregate uncertainty. As a result, banks faced no randomness either in withdrawal demand or in the speed of note redemption. In addition, banks in our model could not issue banknotes in order to lend them. Nor could banking conditions influence the level of real activity. All of these are clearly important features to incorporate in order to better understand private note issue, and we hope to introduce them in future work. 
Appendix

\section{A. Proof of Proposition 2}

If $e_{t+1} \geq 1$ holds, then-as we have noted $-\gamma_{t+1}=\sigma x \gamma_{t}$. Substituting this condition into

(12) we obtain

$$
\frac{(1-\pi)+\pi\left(e_{t+1}\right)^{1 / \rho}}{(1-\pi)+\pi\left(e_{t+1}\right)^{(1-\rho) / \rho}}=1 .
$$

This clearly implies that $e_{t+1}=1$.

\section{B. Proof of Lemma 1}

(a) From the definition of $f$ it is clear that

$$
f(1 / \sigma x)=\left[(1-\pi) \sigma x+\pi(\sigma x)^{(\rho-1) / \rho}\right] /\left[(1-\pi)+\pi(\sigma x)^{(\rho-1) / \rho}\right] .
$$

It is then easy to verify that $\sigma x>f(1 / \sigma x)>1$.

(b) For $\rho \geq 1$ this is obvious.

For $\rho<1$ the claim follows from an application of L' Hopital's rule.

(c) Straightforward differentiation establishes that

(A.2) $\left.z f^{\prime}(z) / f(z)=\left[(\pi / \rho) z^{1 / \rho} /\left(1-\pi+\pi z^{1 / \rho}\right)\right]-[\pi(1-\rho) / \rho] z^{(1-\rho) / \rho}\right] /\left[1-\pi+\pi z^{(1-\rho) / \rho}\right]$.

It is easy to check that, when $\rho<1$ holds, $f^{\prime}(z) \leq 0$ is satisfied iff $z \leq \hat{z}$, where $\hat{z}$ is defined by the relation

$$
\text { (A.3) } \pi \rho \hat{z}^{(1-\rho) / \rho}=(1-\pi)\left[(1-\rho) \hat{z}^{-1}-1\right] \text {. }
$$

This is equivalent to the claim in the text. 


\section{Proof of Proposition 3}

We must show that, when $\rho \neq 1$, satisfaction of (16) implies the satisfaction of $\left(15^{\prime}\right)$. In particular,

(A.4) $\sigma x \gamma_{t}\left[\left(\frac{1-\pi}{\pi}\right)\left(\frac{\gamma_{t}}{1-\gamma_{t}}\right)\right]^{\frac{\rho}{1-\rho}} \equiv \sigma x\left(\gamma_{t}-1\right)+f\left\{\left[\left(\frac{1-\pi}{\pi}\right)\left(\frac{\gamma_{t}}{1-\gamma_{t}}\right)\right]^{\frac{\rho}{1-\rho}}\right\}$

must hold. To establish that it does, note that

$$
f\left\{\left[\left(\frac{1-\pi}{\pi}\right)\left(\frac{\gamma_{t}}{1-\gamma_{t}}\right)\right]^{\frac{\rho}{1-\rho}}\right\}=\sigma x\left(1-\gamma_{t}\right)\left\{1+\left(\frac{\pi}{1-\pi}\right)\left[\left(\frac{1-\pi}{\pi}\right)\left(\frac{\gamma_{t}}{1-\gamma_{t}}\right)\right]^{\frac{1}{1-\rho}}\right\}
$$

Therefore,

(A.5) $\sigma x\left(\gamma_{t}-1\right)+f\left\{\left[\left(\frac{1-\pi}{\pi}\right)\left(\frac{\gamma_{t}}{1-\gamma_{t}}\right)\right]^{\frac{\rho}{1-\rho}}\right\}=\sigma x\left(1-\gamma_{t}\right)\left(\frac{\pi}{1-\pi}\right)\left[\left(\frac{1-\pi}{\pi}\right)\left(\frac{\gamma_{t}}{1-\gamma_{t}}\right)\right]^{\frac{1}{1-\rho}}$.

Substituting (A.5) into (A.4) and rearranging terms, we observe that (A.4) is satisfied iff

(A.6) $\left[\left(\frac{1-\pi}{\pi}\right)\left(\frac{\gamma_{t}}{1-\gamma_{t}}\right)\right]^{\frac{\rho}{1-\rho}} \equiv\left(\frac{\pi}{1-\pi}\right)\left(\frac{1-\gamma_{t}}{\gamma_{t}}\right)\left[\left(\frac{1-\pi}{\pi}\right)\left(\frac{\gamma_{t}}{1-\gamma_{t}}\right)\right]^{\frac{1}{1-\rho}}$.

But (A.6) obviously holds.

\section{Proof of Proposition 4}

Let

(A.7) $g\left(\gamma_{t}\right) \equiv \sigma x \gamma_{t}\left[\left(\frac{1-\pi}{\pi}\right)\left(\frac{\gamma_{t}}{1-\gamma_{t}}\right)\right]^{\frac{\rho}{1-\rho}}$ 
In addition, let $g^{2}\left(\gamma_{t}\right) \equiv g\left[g\left(\gamma_{t}\right)\right]$, and $g^{n}\left(\gamma_{t}\right) \equiv g\left[g^{n-1}\left(\gamma_{t}\right)\right] ; n=2,3, \ldots$ Then an economy that spends $m$ periods with $I_{t}=1$ followed by $n$ periods with $I_{t}>1$ (and then repeating) must have a value of the reserve-deposit ratio satisfying

(A.8) $\gamma_{m n}=(\sigma x)^{m} g^{n}\left(\gamma_{m n}\right)$.

We now establish the existence of such a value $\gamma_{m n}$ for every pair $(m, n)$.

Since $\gamma^{*}=g\left(\gamma^{*}\right)$ and since $\sigma x>1$, clearly $(\sigma x)^{m} g^{n}\left(\gamma^{*}\right)=(\sigma x)^{m} \gamma^{*}>\gamma^{*}$ holds. In addition, clearly

$$
\lim _{\gamma \rightarrow 0} g(\gamma) / \gamma=0
$$

Thus, as $\gamma \downarrow 0,(\sigma x)^{m} g(\gamma) / \gamma \downarrow 0$, so that $1>(\sigma x)^{m} g^{n}(\gamma) / \gamma$ obtains. It therefore follows from the intermediate value theorem that there exists a value $\gamma_{m n} \in\left(0, \gamma^{*}\right)$ satisfying (A.8) for every pair $(m, n)$.

\section{E. Proof of Proposition 5}

From (18) it is easy to show that $b_{t}=0$ holds when $e_{t+1}<1$ iff

$$
\pi\left(\gamma_{t+1} / \sigma x \gamma_{t}\right)^{(1-\rho) / \rho} /\left[1-\pi+\pi\left(\gamma_{t+1} / \sigma x \gamma_{t}\right)^{(1-\rho) / \rho}\right]=\gamma_{t}
$$

Rearranging terms in (A.9), it is straightforward to verify that $b_{t}=0$ holds iff

(A.10) $\gamma_{t+1}=\sigma x \gamma_{t}\left[\left(\frac{1-\pi}{\pi}\right)\left(\frac{\gamma_{t}}{1-\gamma_{t}}\right)\right]^{\rho /(1-\rho)}$.

But a comparison of (A.10) and (16) will quickly indicate that (A.10) holds whenever $e_{t+1}<1$.

\section{F. Proof of Proposition 6}

That $\alpha_{t}=0$ holds is obvious from (26) and the hypothesis that $I_{t}>1$. To establish the remainder of the proposition, impose $\alpha_{t}=0$ in (26). Then the bank's problem is equivalent to 
$\max \pi\left(d_{t}^{m}\right)^{1-\rho} /(1-\rho)+(1-\pi)\left(d_{t}^{n}\right)^{1-\rho} /(1-\rho)$

subject to

$$
\pi d_{t}^{m}+(1-\pi) d_{t}^{n}\left(1 / I_{t}\right)=y_{t}
$$

It is easy to verify that the solution to this problem satisfies (28) and (29).

\section{G. Proof of Proposition 7}

(a) As noted in the text, steady state equilibria are solutions to (35). As $\gamma_{s}^{*} \uparrow 1$, the lefthand side of (35) approaches $1 / f(1 / \sigma x)<1$. As $\gamma_{s}^{*} \downarrow 0$, the left-hand side of (35) approaches $\sigma x / f(1 / \sigma x)$. (36) implies that this exceeds the right-hand side of (35). Thus, by the intermediate value theorem, a steady state with $\gamma_{s}^{*} \in(0,1)$ exists.

(b) In the absence of a Suffolk Banking System the unique nontrivial steady state $\gamma^{*}$ satisfies

(A.11) $\frac{\sigma x-(\sigma x-1) \gamma^{*}}{f(1 / \sigma x)}=1$.

Since the left-hand sides of (35) and (A.11) are decreasing in $\gamma$, the result is immediate.

\section{H. Proof of Proposition 8}

(a) That $Q(0)=Q[1-\lambda(1-\pi)]=0$ is obvious. For the remainder of the claim note that $\lambda \pi>1-\lambda(1-\pi)=\lambda \pi+(1-\lambda)$ holds, since $\lambda>1$. Thus $\forall \gamma \in(0,[1-\lambda(1-\pi)])$ both the numerator and the denominator of $Q$ are positive.

(b) From the definition of $Q$ we have

(A.12) $\frac{\gamma Q^{\prime}(\gamma)}{Q(\gamma)}=\left(\frac{\lambda \pi}{\lambda \pi-\gamma}\right)-\left[\frac{\gamma}{1-\gamma-\lambda(1-\pi)}\right]$.

Then $Q^{\prime}(\gamma) \geq 0$ holds iff 
(A.13) $\gamma^{2}-2 \lambda \pi \gamma+\lambda \pi[1-\lambda(1-\pi)] \geq 0$.

If we define $\tilde{\gamma}$ to be the solution to (A.13) at equality (and if we require that $\tilde{\gamma}<1-\lambda(1-\pi)$

hold), then (A.13) holds iff $\gamma \in[0, \tilde{\gamma}]$, as claimed. Moreover, it is easy to check that

$$
\tilde{\gamma}=\lambda \pi-\{\lambda \pi[\lambda \pi-1+\lambda(1-\pi)]\}^{1 / 2}=\lambda \pi-[(\lambda \pi)(\lambda-1)]^{1 / 2}
$$

\section{Proof of Lemma 2}

It is clear from the definition of $Q$ [equation (38)] that $Q(\widetilde{\gamma})>\widetilde{\gamma}$ holds iff

(A.14) $\sigma x[1-\lambda(1-\pi)-\tilde{\gamma}]>\lambda \pi-\widetilde{\gamma}$

(since $\lambda \pi>\tilde{\gamma}$ ). Using the expression for $\tilde{\gamma}$ in part (b) of Proposition 8, it is easy check that

(A.14) reduces to

$\left(\mathrm{A} .14^{\prime}\right)(\sigma x-1)[\lambda \pi(\lambda-1)]^{1 / 2}>\sigma x(\lambda-1)$

Rearranging terms in (A.14') yields (38).

\section{J. Proof of Proposition 9}

From the definition of $Q, Q(\tilde{\gamma})>1-\lambda(1-\pi)$ is satisfied iff

(A.15) $\sigma x \widetilde{\gamma}[1-\lambda(1-\pi)-\tilde{\gamma}]>[1-\lambda(1-\pi)][\lambda \pi-\tilde{\gamma}]$

Using the expression for $\widetilde{\gamma}$ in part (b) of Proposition 8 in (A.15) and rearranging terms, we obtain that $Q(\tilde{\gamma})>1-\lambda(1-\pi)$ holds iff

$\left(\mathrm{A} .15^{\prime}\right) \tilde{\gamma}>(\lambda \pi / \sigma x)\left\{1+[(\lambda-1) / \lambda \pi]^{1 / 2}\right\}$

And, in turn, (A.15') has the equivalent representation

(A.16) $\lambda \pi-[\lambda \pi(\lambda-1)]^{1 / 2}>(\lambda \pi / \sigma x)\left\{1+[(\lambda-1) / \lambda \pi]^{1 / 2}\right\}$.

Rearranging terms in (A.16), one obtains (40). 


\section{K. Proof of Proposition 10}

It follows from (A.12) that

(A.17) $\gamma_{s}^{*} Q^{\prime}\left(\gamma_{s}^{*}\right) / Q\left(\gamma_{s}^{*}\right)=Q^{\prime}\left(\gamma_{s}^{*}\right)=\left[\lambda \pi /\left(\lambda \pi-\gamma_{s}^{*}\right)\right]-\gamma_{s}^{*} /\left[1-\lambda(1-\pi)-\gamma_{s}^{*}\right]$.

Moreover, $\gamma_{s}^{*}$ satisfies

(A.18) $\lambda \pi-\gamma_{s}^{*}=\sigma x\left[1-\lambda(1-\pi)-\gamma_{s}^{*}\right]$

Substituting (A.18) into (A.17), it is clear that $Q^{\prime}\left(\gamma_{s}^{*}\right)>-1$ is satisfied iff

(A.19) $\left(\lambda \pi-\sigma x \gamma_{s}^{*}\right)>\gamma_{s}^{*}-\lambda \pi$.

Rearranging terms in (A.19) one readily obtains the equivalent condition

$\left(\mathrm{A} .19^{\prime}\right) 2 \lambda \pi>(\sigma x+1) \gamma_{s}^{*}$.

Furthermore, (A.18) implies that

$\left(\mathrm{A} .18^{\prime}\right) \gamma_{s}^{*}=\{\sigma x[1-\lambda(1-\pi)]-\lambda \pi\} /(\sigma x-1)$.

(A.18') and (A.19') then imply that $\mathrm{Q}^{\prime}\left(\gamma_{s}^{*}\right)>-1$ holds iff

(A.20) $2 \lambda \pi>\left[\frac{(\sigma x+1) \sigma x}{\sigma x-1}\right][1-\lambda(1-\pi)]-\left(\frac{\sigma x+1}{\sigma x-1}\right) \lambda \pi$

Rearranging terms in (A.20) one obtains the desired result.

Parenthetically, if $Q^{\prime}\left(\gamma_{s}^{*}\right)>0$ holds, it is easy to verify that

$$
\mathrm{Q}^{\prime}\left(\gamma_{s}^{*}\right)=\left(\lambda \pi-\sigma x \gamma_{s}^{*}\right) /\left(\lambda \pi-\gamma_{s}^{*}\right)<1
$$




\section{References}

Azariadis, Costas, and Smith, Bruce D. 1998. Financial intermediation and regime switching in business cycles. American Economic Review 88 (June): 516-36.

Calomiris, Charles W., and Kahn, Charles M. 1996. The efficiency of self-regulated payments systems: Learning from the Suffolk System. Journal of Money, Credit, and Banking 28 (November, Part 2): 766-97.

Champ, Bruce; Smith, Bruce D.; and Williamson, Stephen D. 1996. Currency elasticity and banking panics: Theory and evidence. Canadian Journal of Economics 29 (November): 828-64.

Devaney, R. L. 1989. An introduction to chaotic dynamical systems. New York: AddisonWesley.

Diamond, Douglas W., and Dybvig, Phillip H. 1983. Bank runs, deposit insurance, and liquidity. Journal of Political Economy 91 (June): 401-19.

Friedman, Milton. 1960. A program for monetary stability. New York: Fordham University Press.

Genay, Hesna. 1995. The financial characteristics and profitability of banks in the antebellum capital markets. Manuscript. Federal Reserve Bank of Chicago.

Gorton, Gary. 1989. An introduction to Van Court's note reporter and counterfeit detector. Manuscript. Wharton School, University of Pennsylvania.

Hayek, Friedrich A. 1976. The denationalization of money. London: Institute of Economic Affairs.

Lake, Wilfred S. 1947. The end of the Suffolk System. Journal of Economic History 7 (November): 183-207. 
Mints, Lloyd W. 1945. A history of banking theory in Great Britain and the United States. Chicago: University of Chicago Press.

Mullineaux, Donald J. 1987. Competitive monies and the Suffolk Bank System: A contractual perspective. Southern Economic Journal 53 (April): 884-98.

Redlich, Fritz. 1947. The molding of American banking: Men and ideas. New York: Hafner.

Rockoff, Hugh. 1975. The Free Banking Era: A re-examination. New York: Arno.

Rolnick, Arthur J.; Smith, Bruce, D.; and Weber, Warren E. 1998. Lessons from a laissez-faire payments system: The Suffolk Banking System (1825-58). Federal Reserve Bank of St. Louis Review (May/June): 105-16. Reprinted in Federal Reserve Bank of Minneapolis Quarterly Review (Summer 1998, pp. 11-21).

Rolnick, Arthur J. and Weber, Warren E. 1983. New evidence on the Free Banking Era. American Economic Review 73 (December): 1080-91.

Rolnick, Arthur J., and Weber, Warren E. 1984. The causes of free bank failures: A detailed examination. Journal of Monetary Economics 14 (November): 267-91.

Rolnick, Arthur J., and Weber, Warren E. 1988. Explaining the demand for free bank notes. Journal of Monetary Economics 21 (January): 47-71.

Sargent, Thomas J., and Wallace, Neil. 1983. A model of commodity money. Journal of Monetary Economics 12 (July): 163-87.

Schreft, Stacey L., and Smith, Bruce D. 1997. Money, banking, and capital formation. Journal of Economic Theory 73 (March): 157-82.

Schreft, Stacey L., and Smith, Bruce D. 1998. The effects of open market operations in a model of intermediation and growth. Review of Economic Studies 65 (July): 519-50.

Temin, Peter. 1969. The Jacksonian economy. New York: Norton. 
Townsend, Robert M. 1987. Economic organization with limited communication. American Economic Review 77 (December): 954-71.

Wallace, Neil. 1988. Another attempt to explain an illiquid banking system: The Diamond and Dybvig model with sequential service taken seriously. Federal Reserve Bank of Minneapolis Quarterly Review (Fall): 3-16.

Whitney, D. R. 1878. The Suffolk Bank. Cambridge, Mass.: Riverside Press. 


\section{Figure 1}

Timing of Events

Young agents receive endowments and make bank deposits.

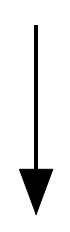

Relocated old agents purchase goods with currency and banknotes.

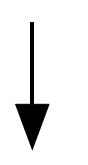

Relocated

agents

withdraw

deposits,

obtaining currency

and banknotes.

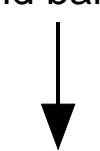

Relocated agents move.

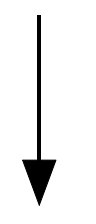

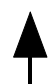

Banks

acquire

cash reserves

and storage.
Relocation

status of

young agents

is revealed.
Banknotes

issued in

the

preceding

period

are cleared. 
Figure 2

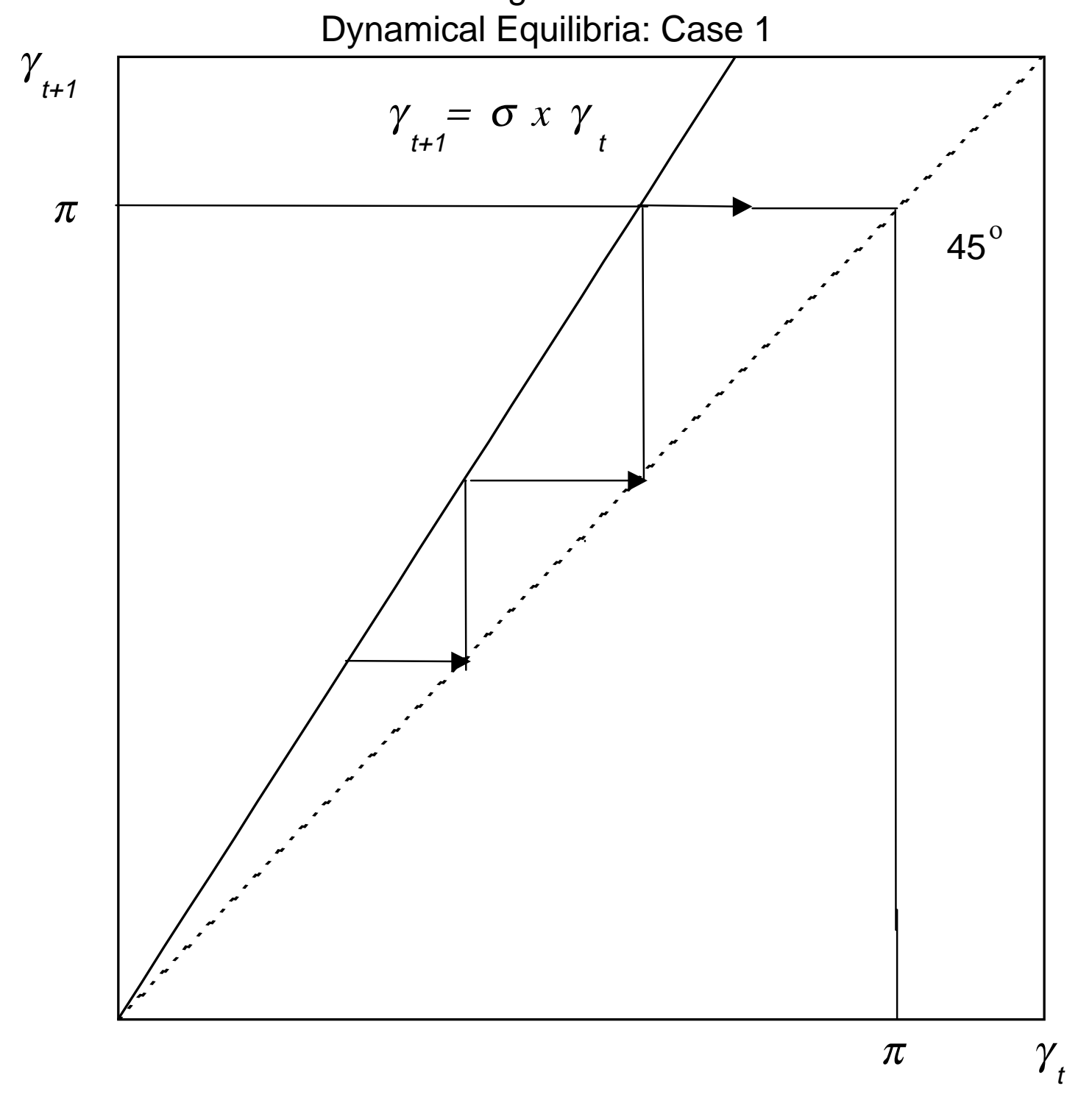


Figure $3 a$

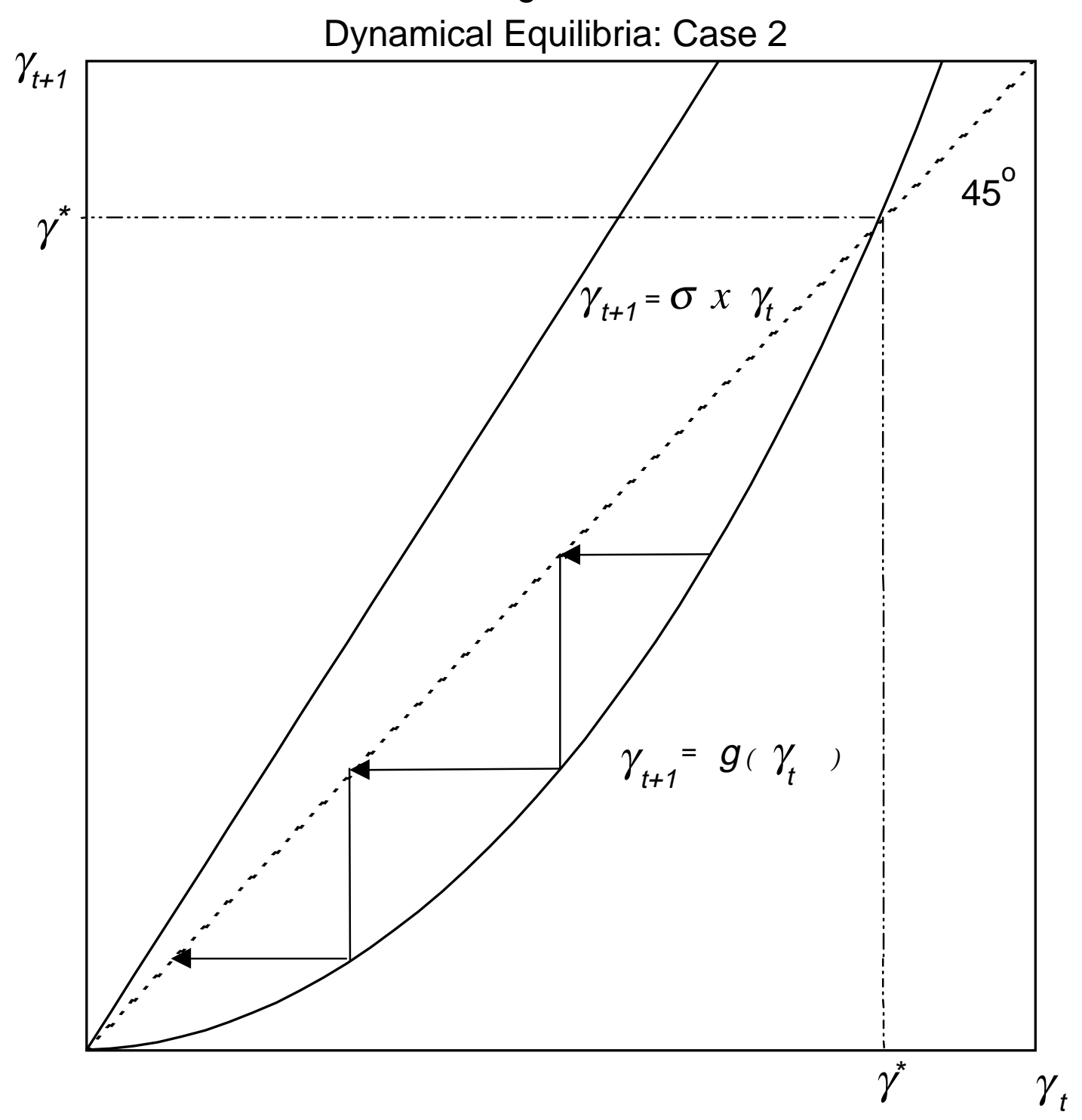


Figure $3 b$

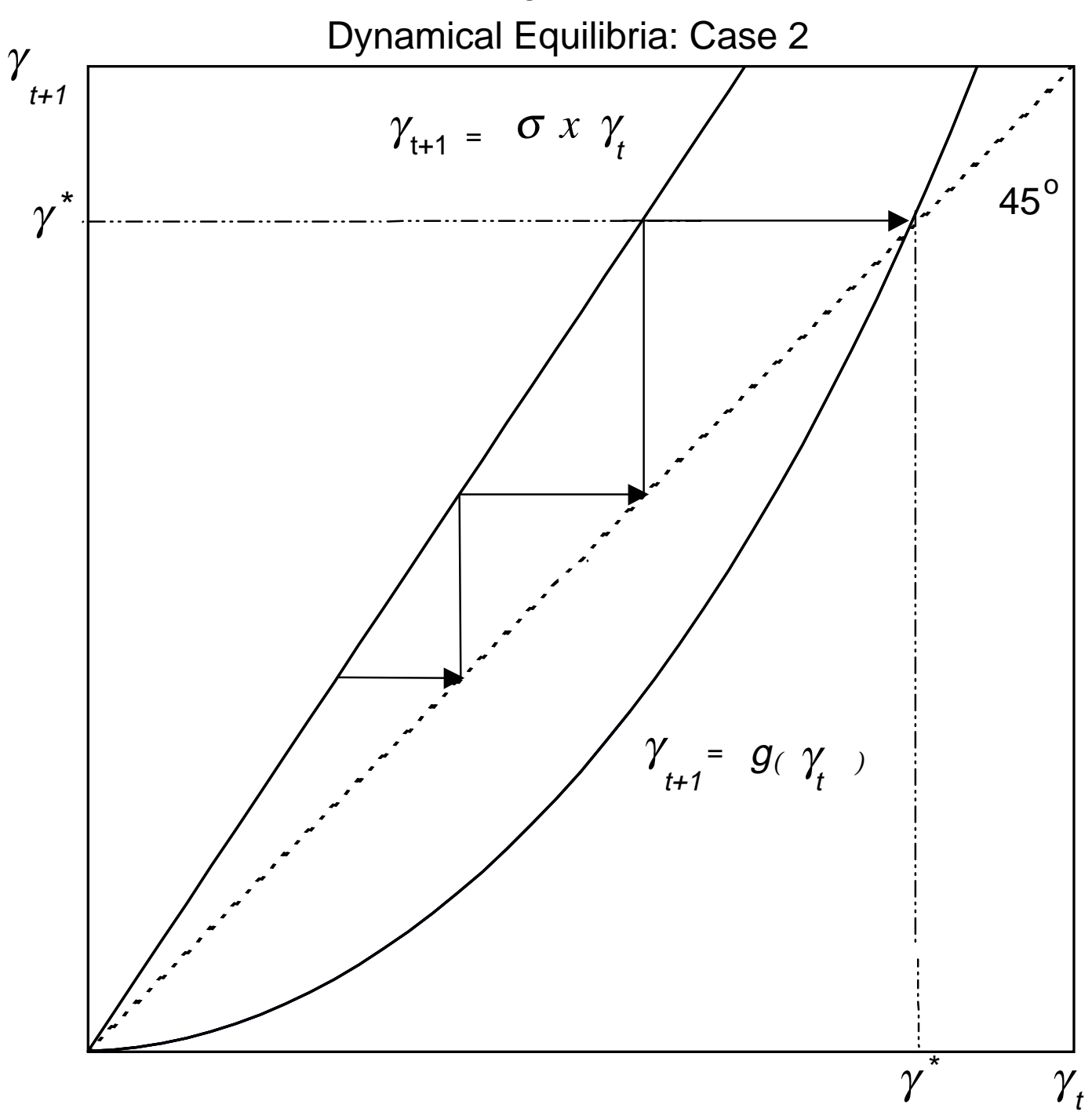


Figure 3c

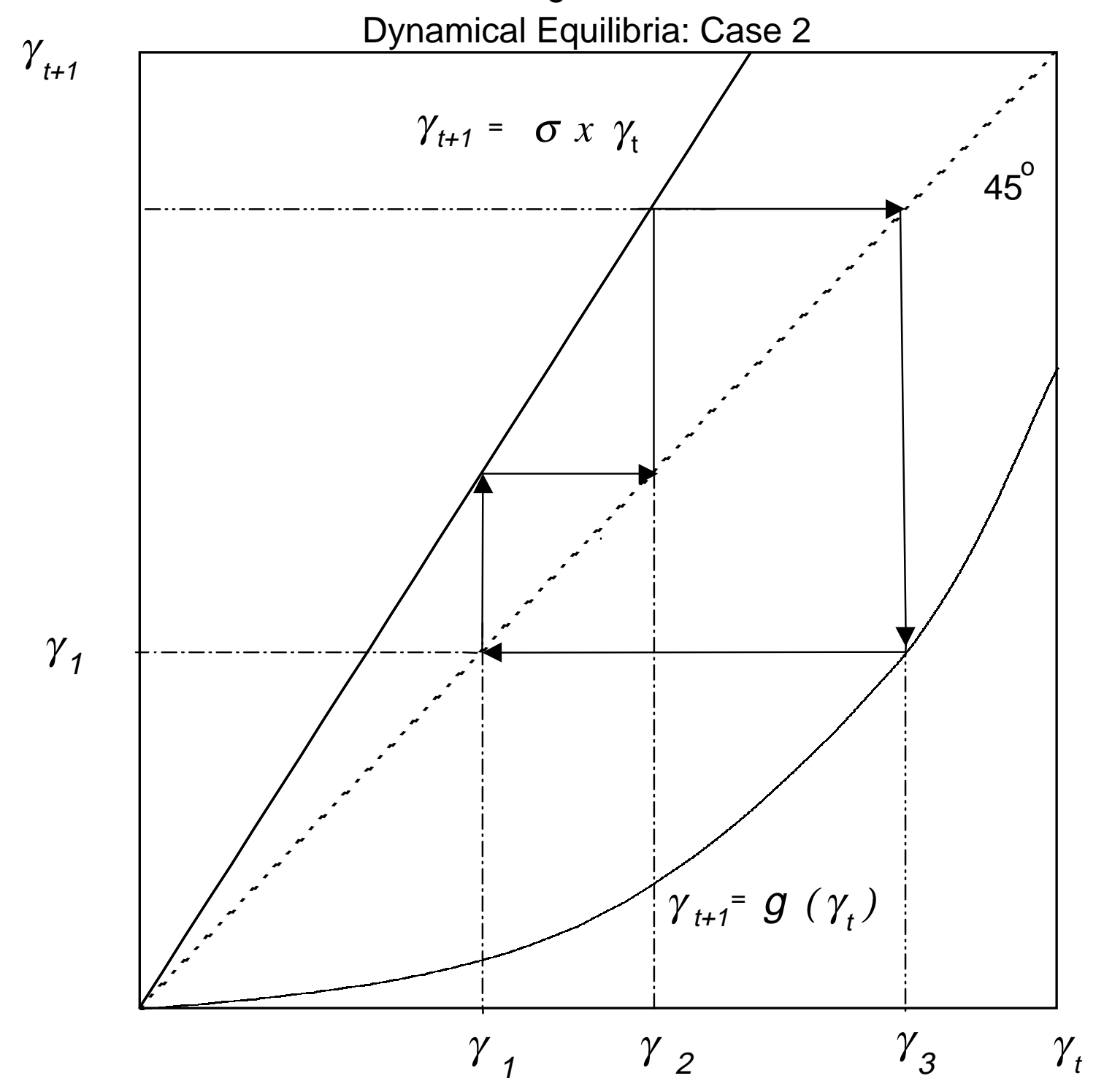


Figure 4

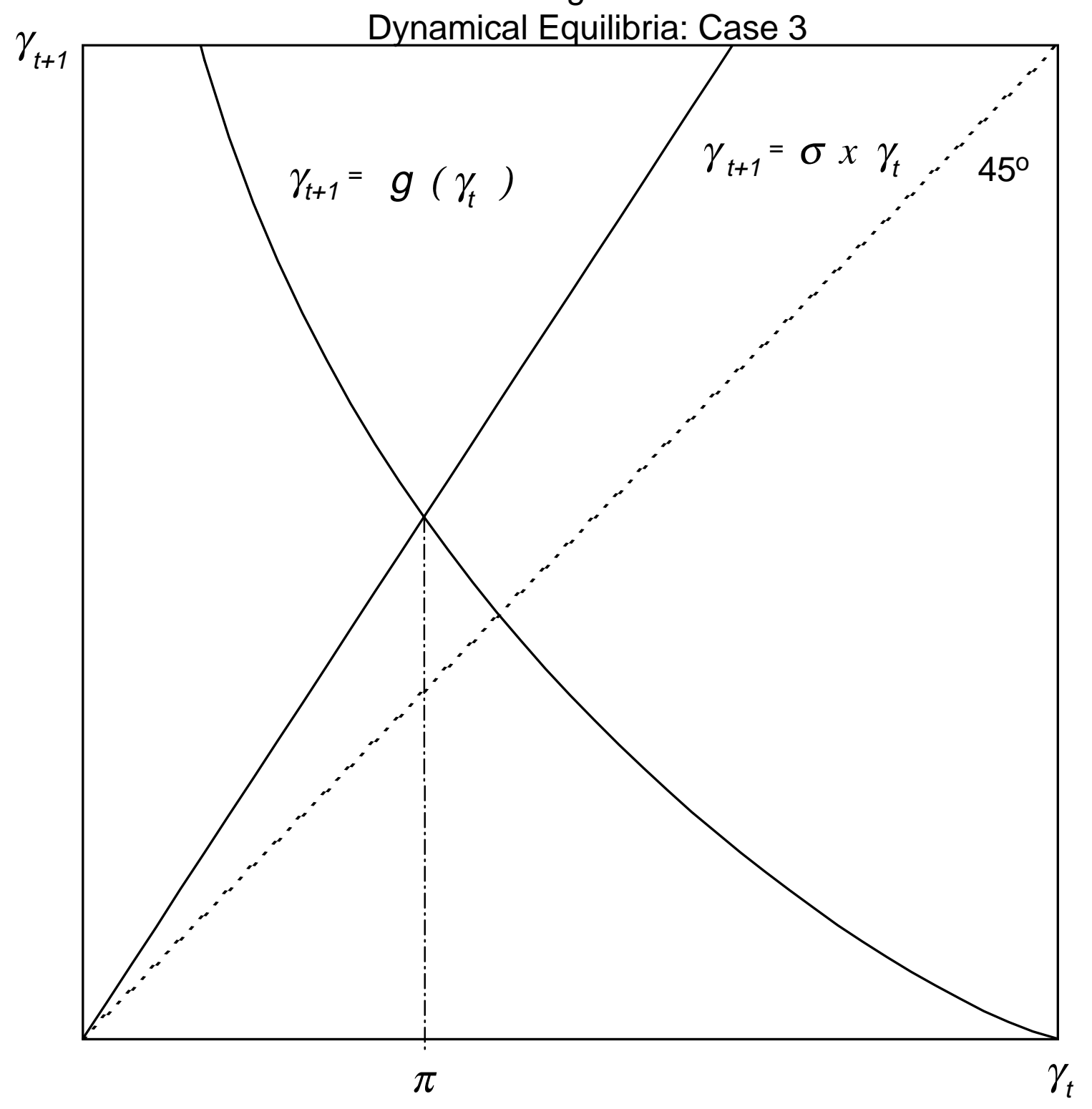


Figure 5

The Spatial Arrangement of the Suffolk System
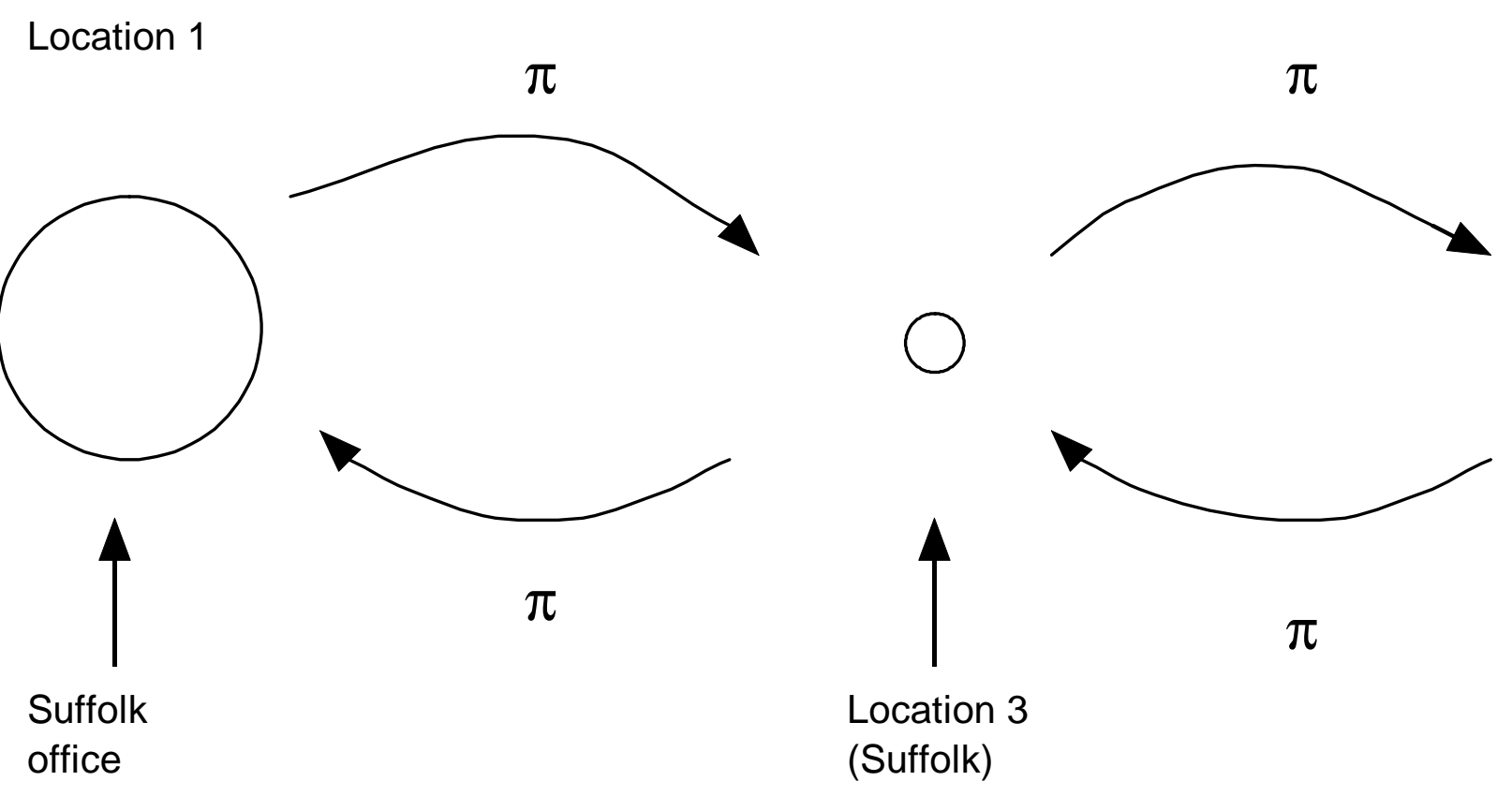

Location 2

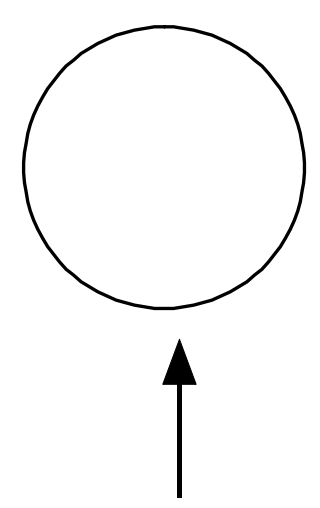

Suffolk office 
Figure $6 a$

Dynamical Equilibria Under a Suffolk Like System

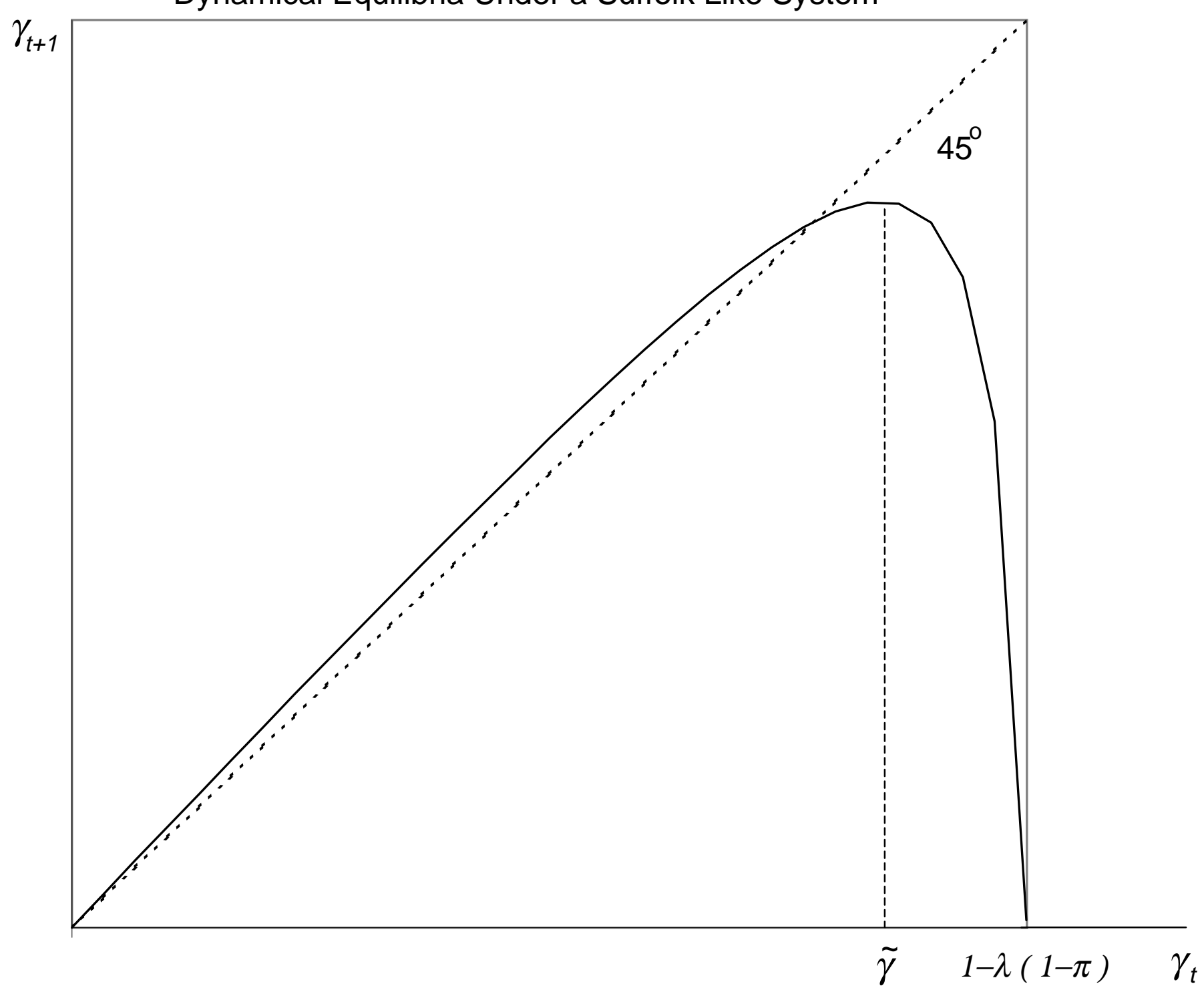


Figure $6 b$

Dynamical Equilibria Under a Suffolk Like System

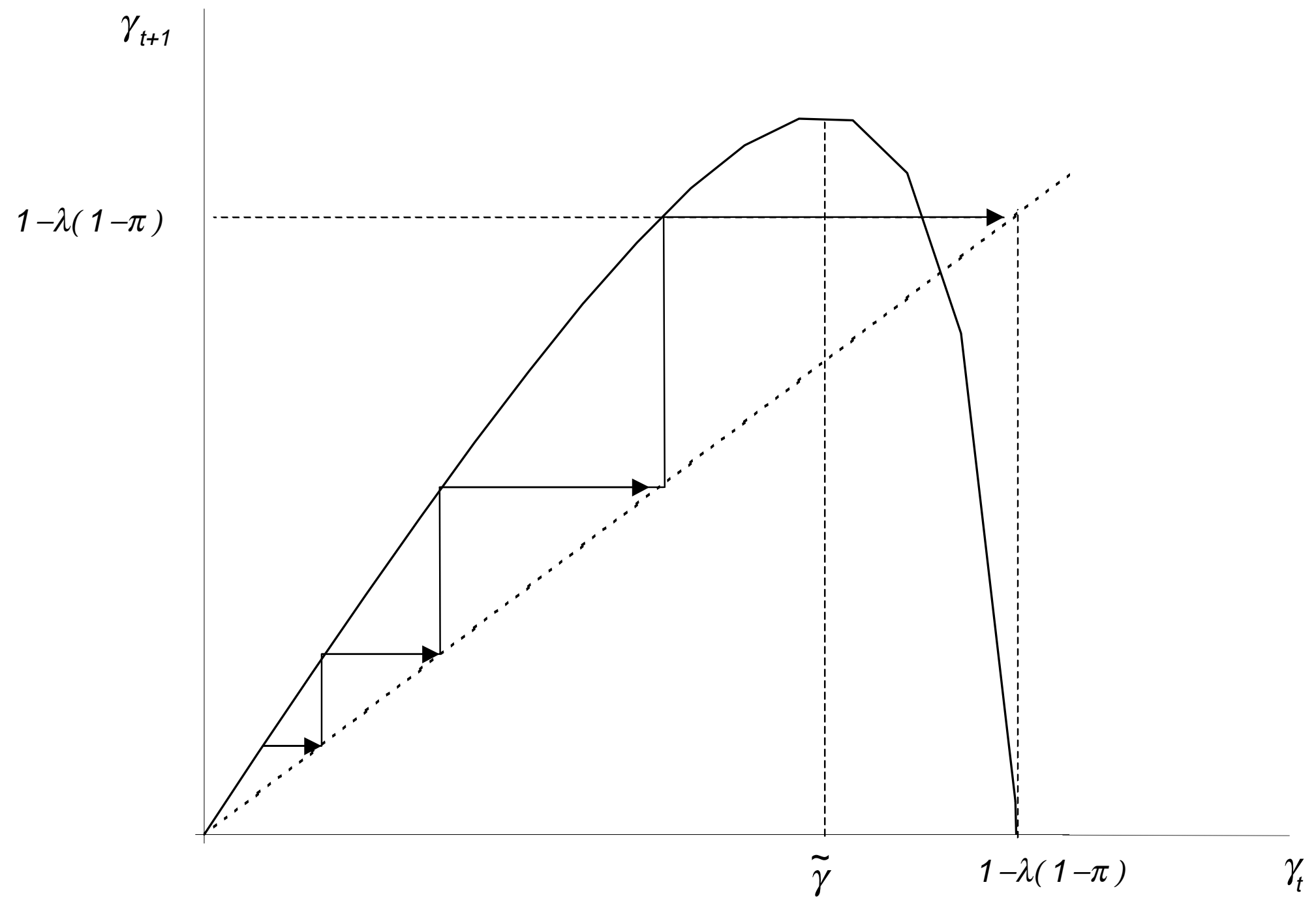


Figure 7a

Specie/Deposits

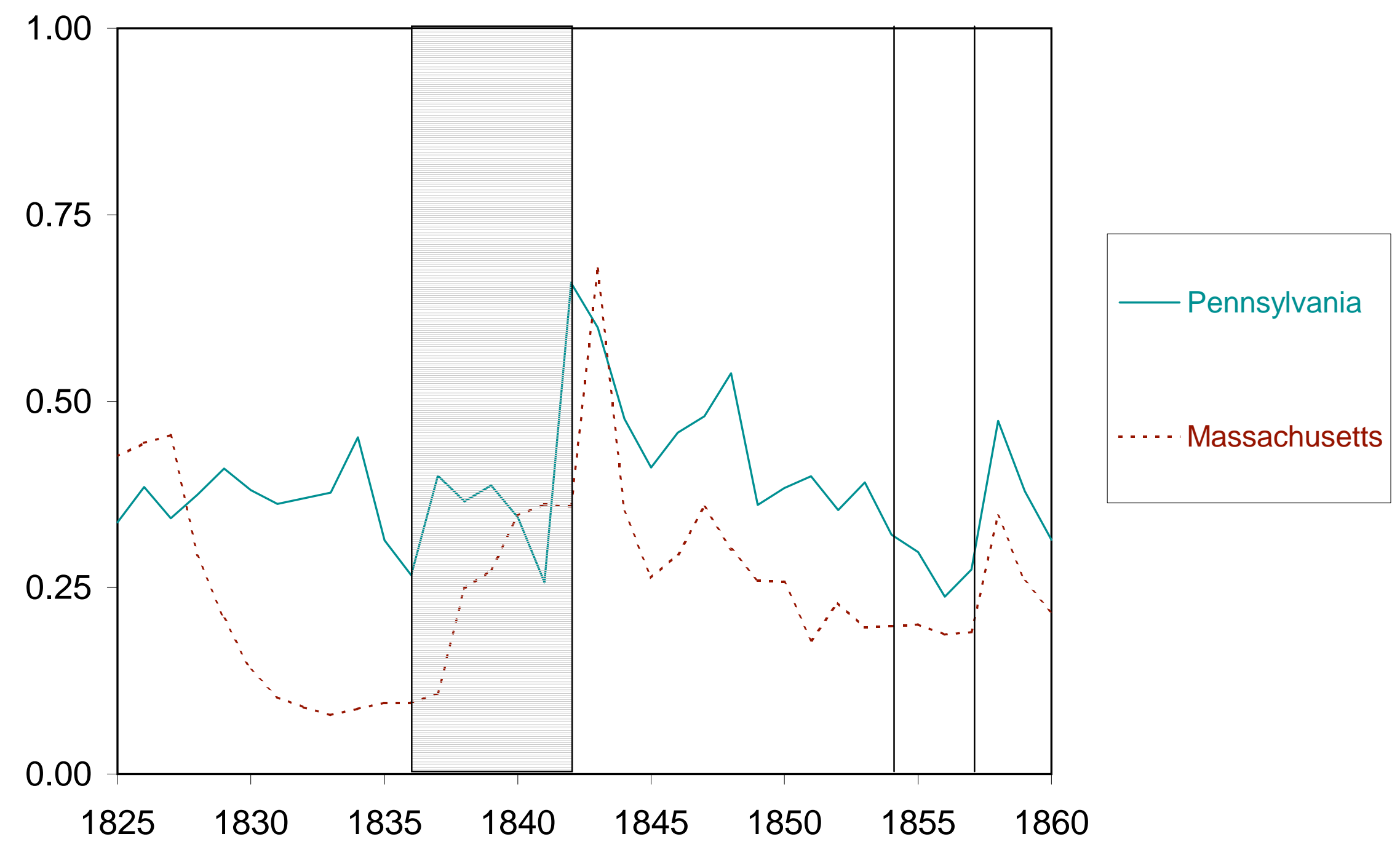


Figure $7 b$

Specie/(Deposits+Capital)

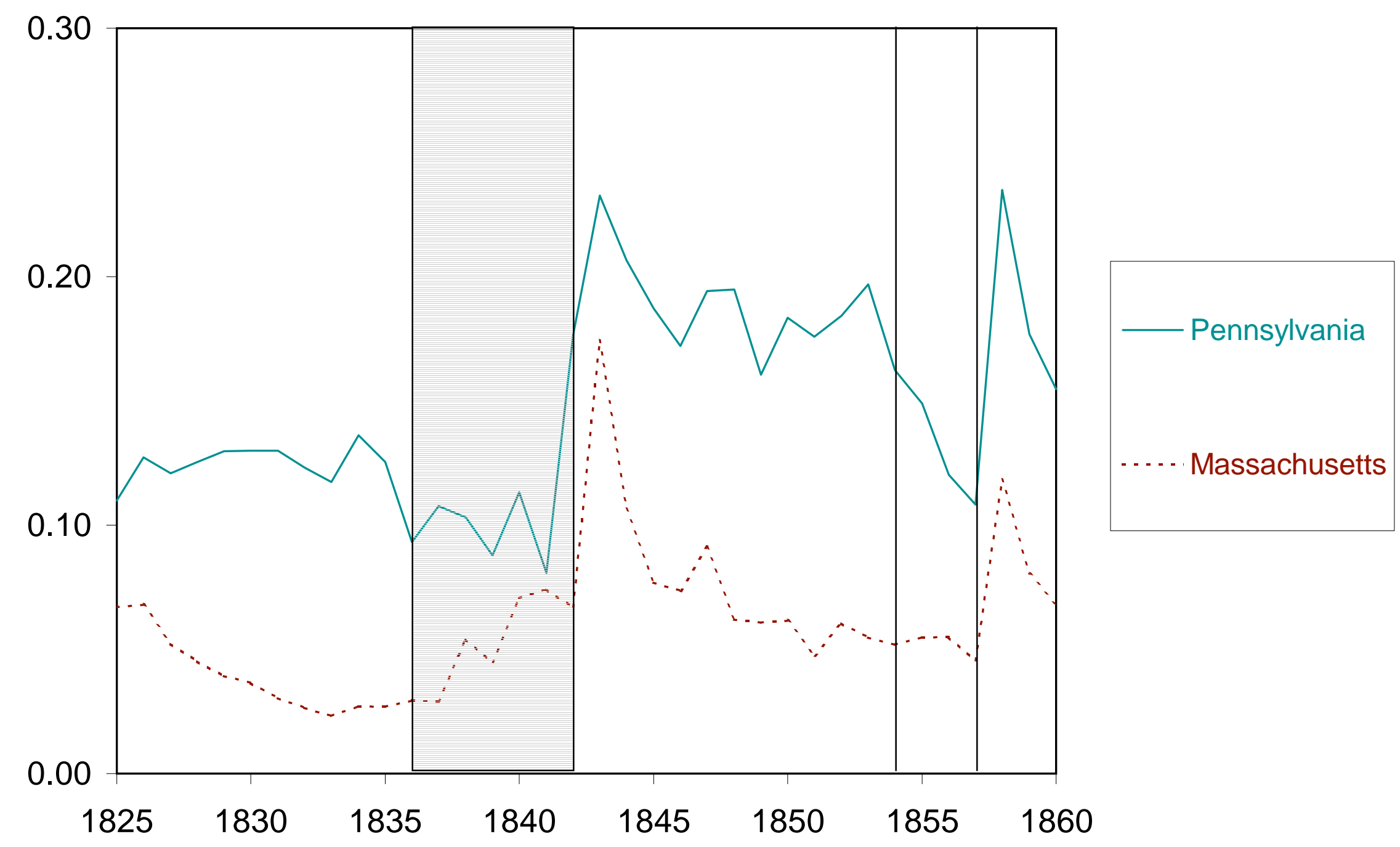


Figure 8

\section{Permanent Deposits and Due Tos and Due Froms,} Suffolk Bank

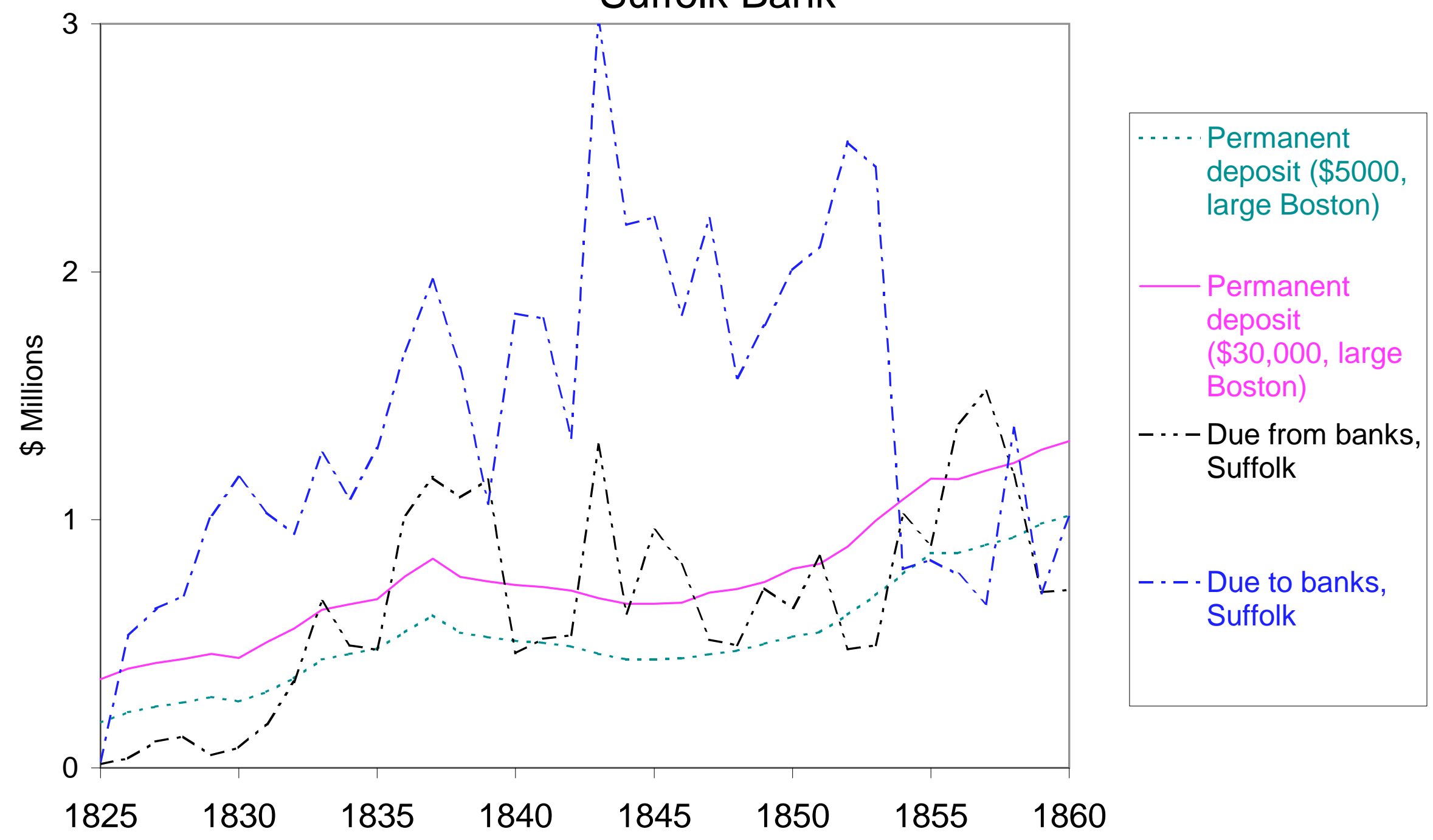


Figure 9a

Bills of Public/Deposits

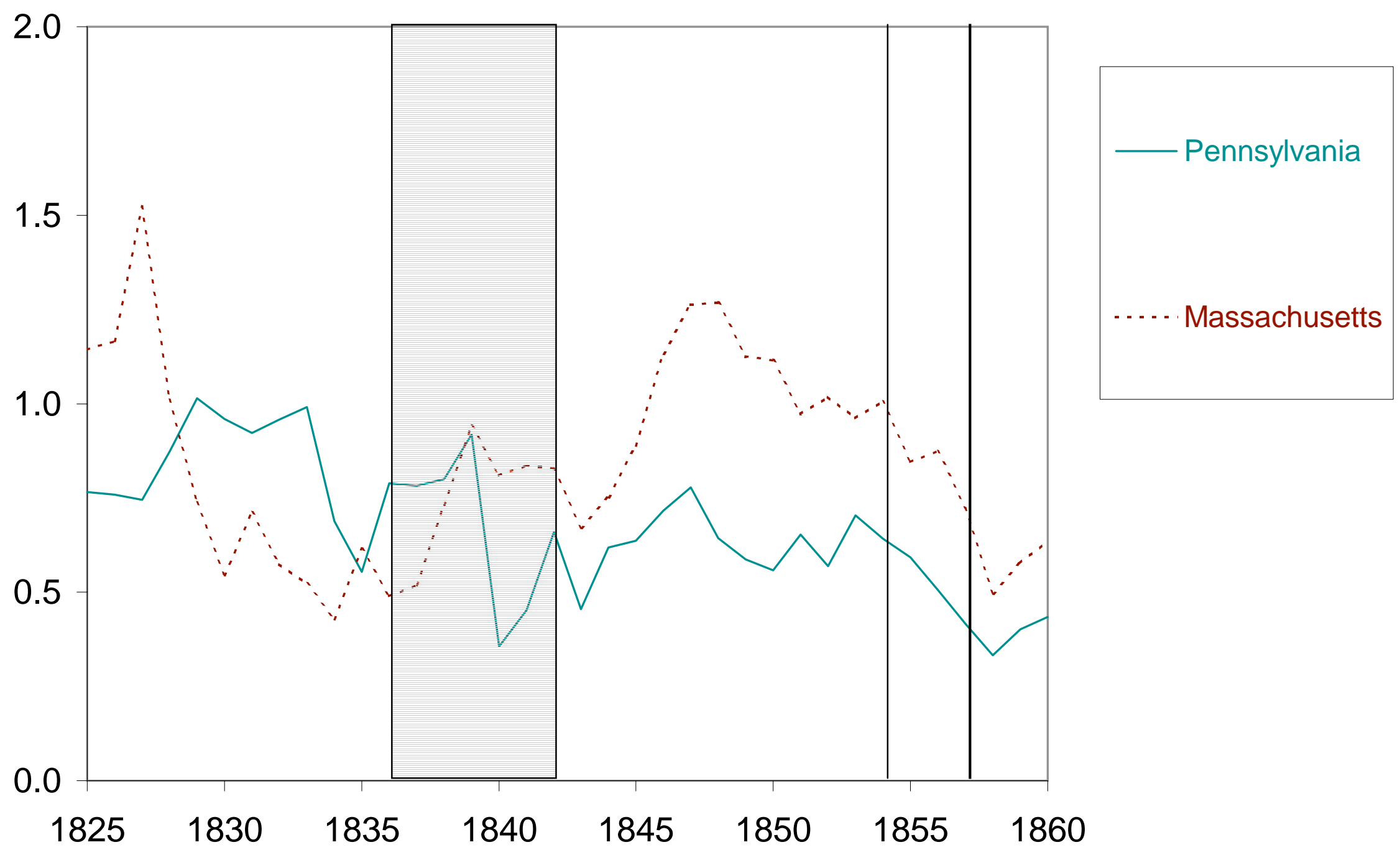


Figure 9b

\section{Bills of Public/(Deposits+Capital)}

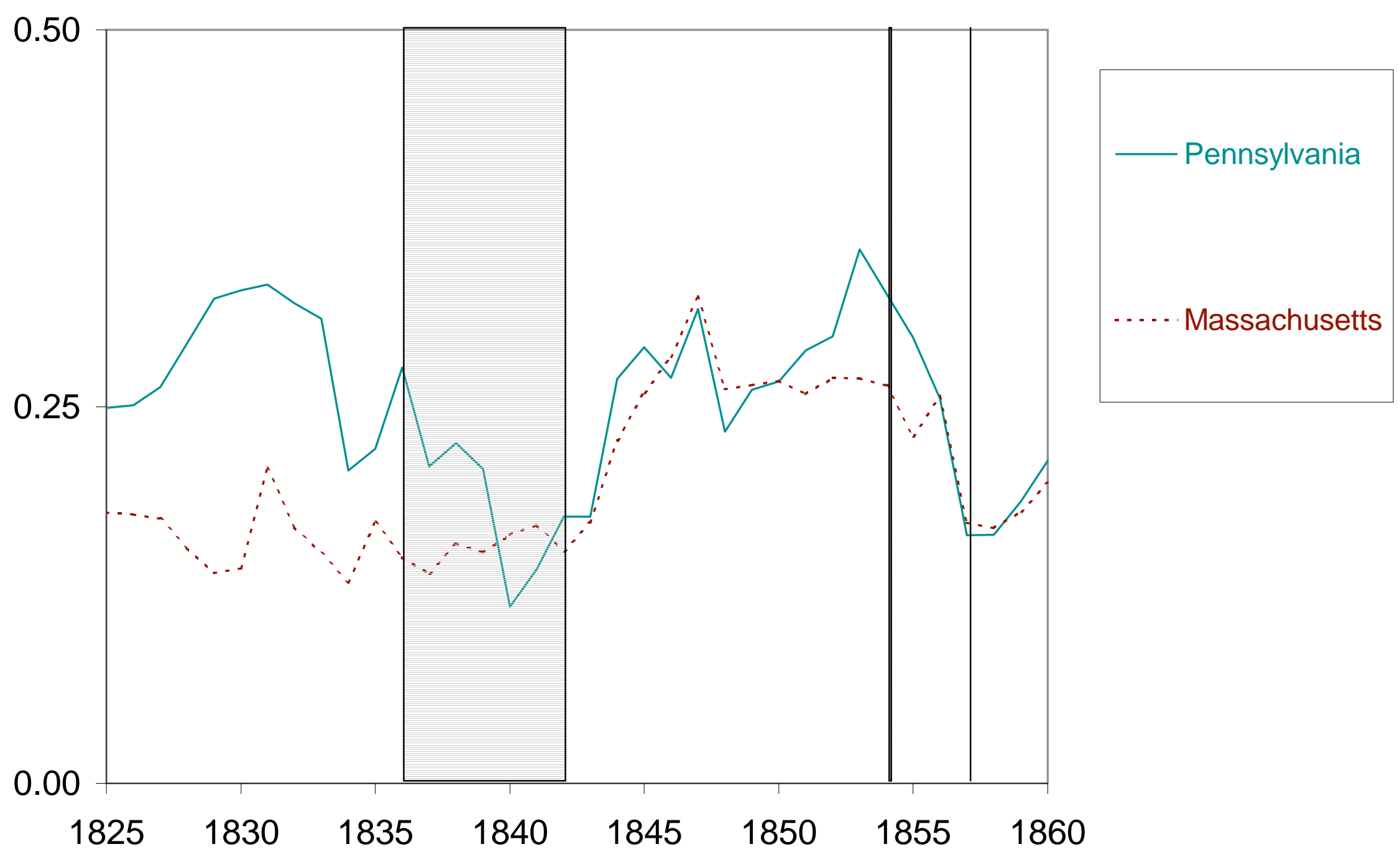


Figure 10a

\section{Loans/Deposits}

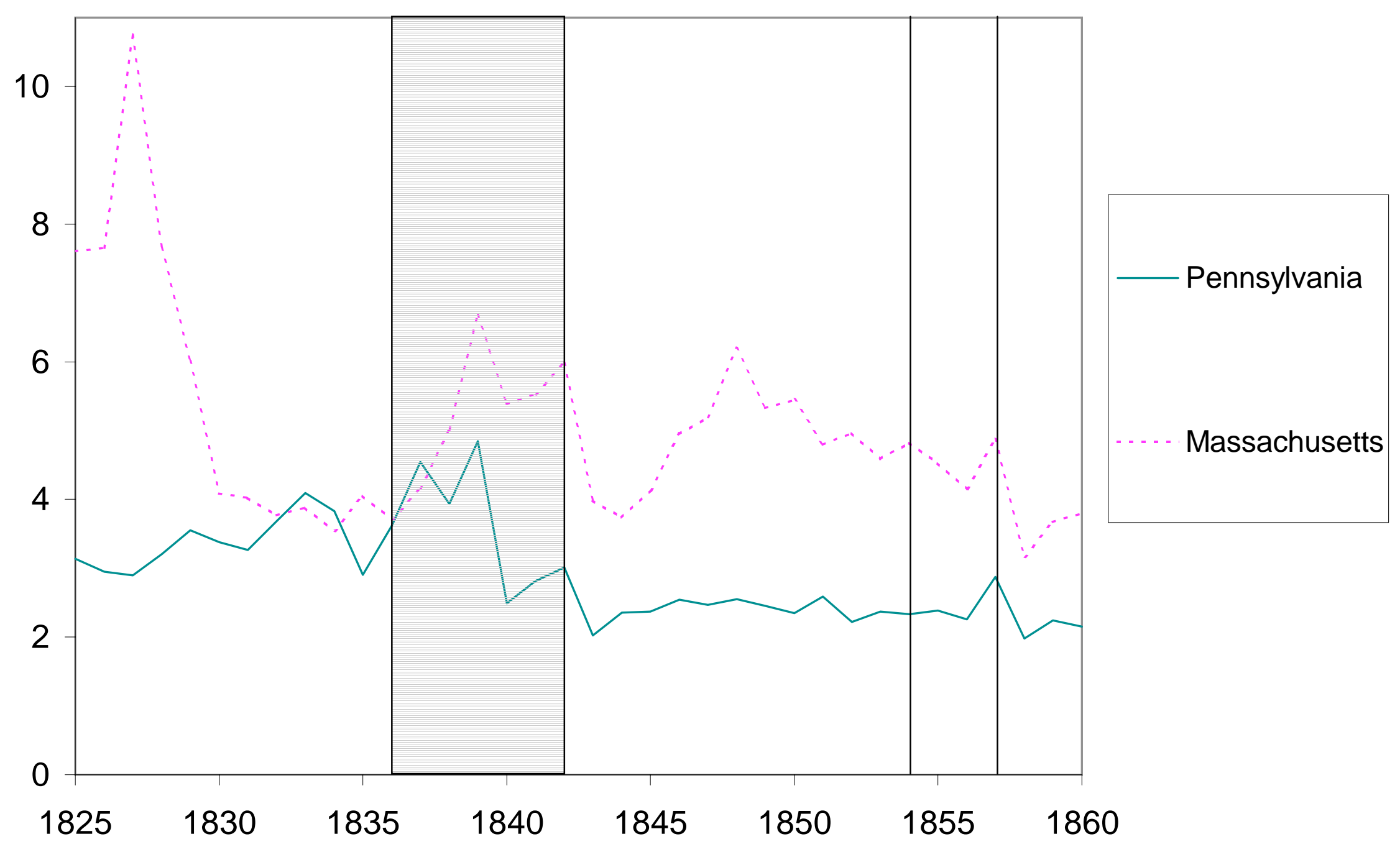


Figure 10b

\section{Loans/(Deposits+Capital)}

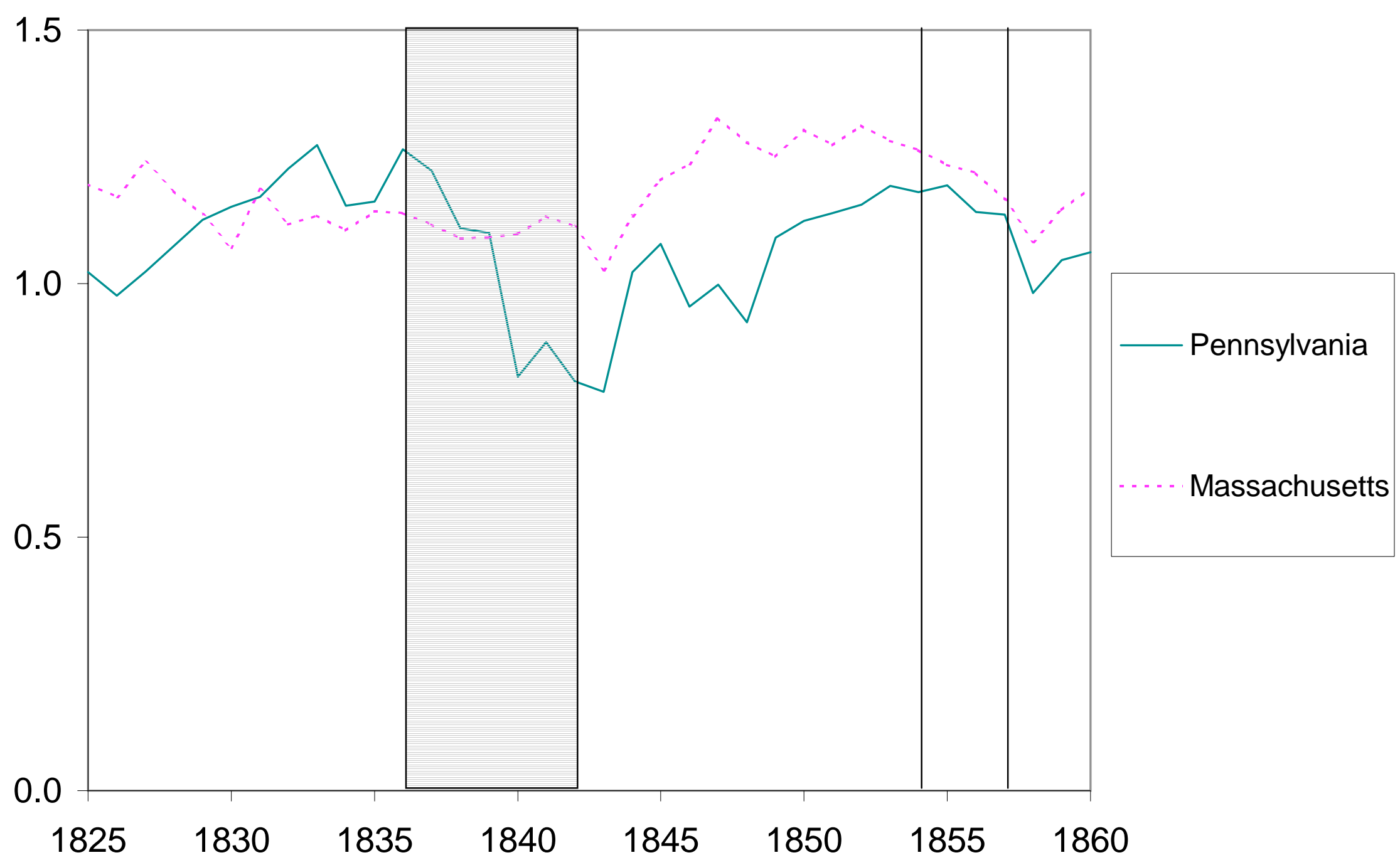


Figure 11a

\section{Due To Minus Due From/Deposits}

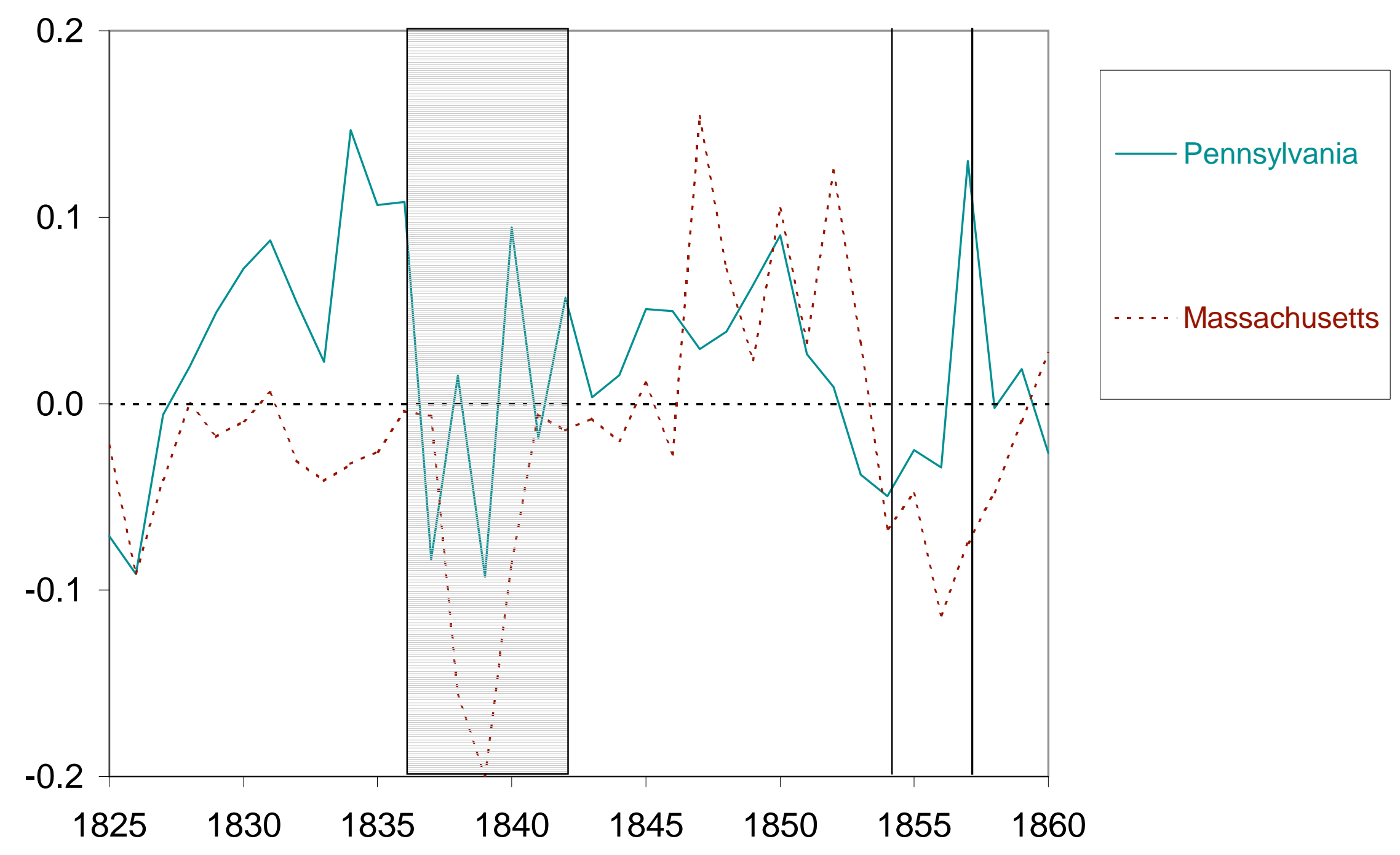


Figure 11b

\section{Due To Minus Due From/(Deposits+Capital)}

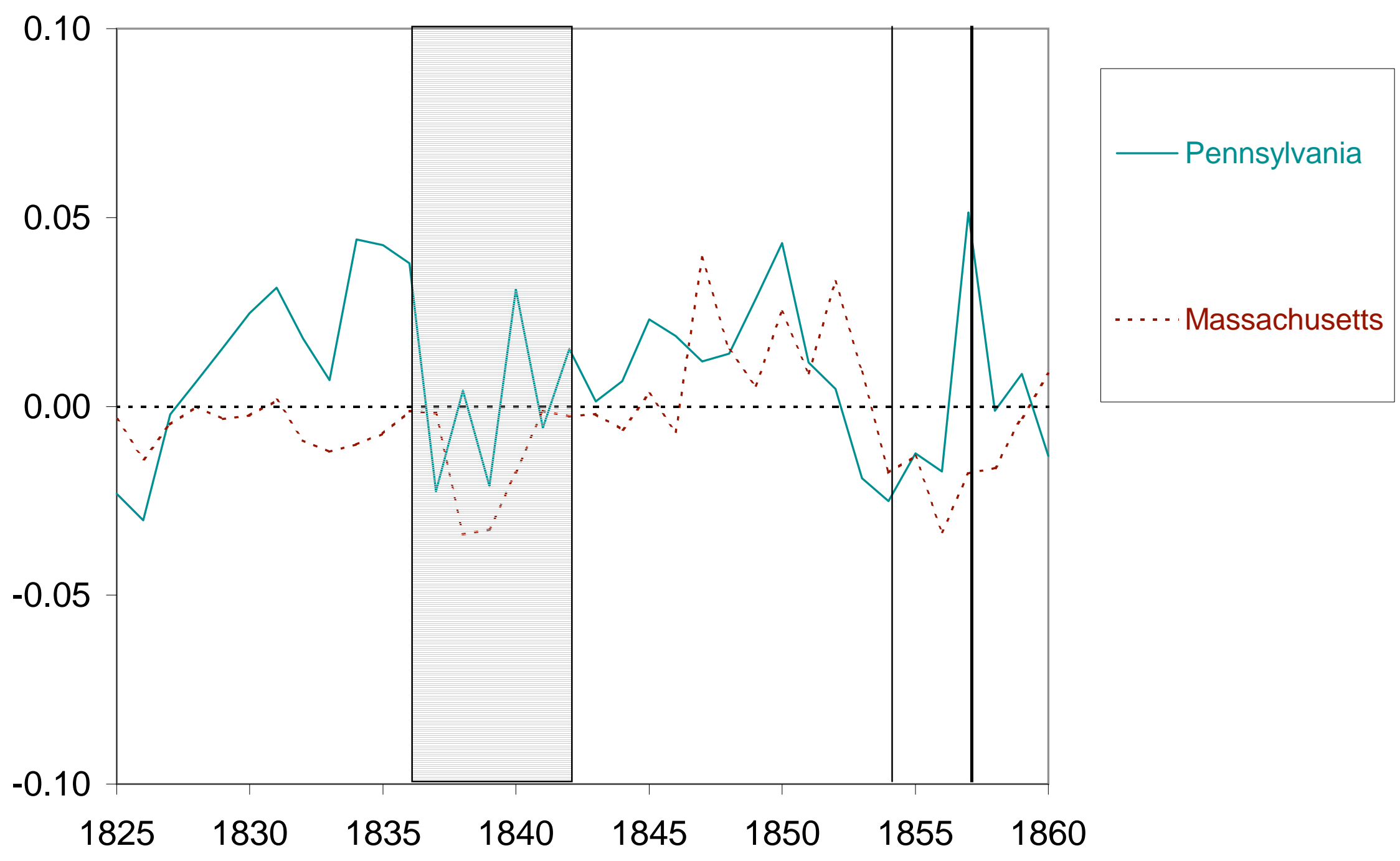

